\title{
Breast Milk Lipidome Is Associated with Early Growth Trajectory in Preterm Infants
}

\author{
Marie-Cécile Alexandre-Gouabau 1,* (D), Thomas Moyon ${ }^{1,+}+$, Véronique Cariou ${ }^{2,+}$ (D), \\ Jean-Philippe Antignac ${ }^{3}$, El Mostafa Qannari ${ }^{2}$, Mikaël Croyal ${ }^{1}$, Mohamed Soumah ${ }^{2}$, \\ Yann Guitton ${ }^{3}$ (D), Agnès David-Sochard ${ }^{1}$, Hélène Billard ${ }^{1}$, Arnaud Legrand ${ }^{4}$, Cécile Boscher ${ }^{4}$, \\ Dominique Darmaun ${ }^{1,4}$, Jean-Christophe Rozé ${ }^{1,4,+}$ and Clair-Yves Boquien 1,5, + (iD \\ 1 Institut National de la Recherche Agronomique (INRA), Unité Mixte de Recherche (UMR) 1280, \\ Physiopathologie des Adaptations Nutritionnelles, Institut des Maladies de L'appareil Digestif (IMAD), \\ Centre de Recherche en Nutrition Humaine Ouest (CRNH), 44093 Nantes, CEDEX 1, France; \\ Thomas.Moyon@univ-nantes.fr (T.M.); mikael.croyal@univ-nantes.fr (M.C.); \\ agnes.david@univ-nantes.fr (A.D.-S.); helene.billard@univ-nantes.fr (H.B.); ddarmaun@gmail.com (D.D.); \\ jeanchristophe.roze@chu-nantes.fr (J.-C.R.); clair-yves.boquien@univ-nantes.fr (C.-Y.B.) \\ 2 Statistique, Sensométrie et Chimiométrie (StatSC), Ecole Nationale Vétérinaire, Agroalimentaire et de \\ l'Alimentation Nantes-Atlantique (ONIRIS), Institut National de la Recherche Agronomique (INRA), \\ 44322 Nantes, France; veronique.cariou@oniris-nantes.fr (V.C.); elmostafa.qannari@oniris-nantes.fr (E.M.Q.); \\ molamine35@yahoo.fr (M.S.) \\ 3 L'Université Nantes Angers Le Mans (LUNAM Université), Ecole Nationale Vétérinaire, Agroalimentaire et \\ de l'Alimentation Nantes-Atlantique (ONIRIS), Laboratoire d'Etude des Résidus et Contaminants dans les \\ Aliments (LABERCA), USC INRA 1329, 44200 Nantes, France; \\ jean-philippe.antignac@oniris-nantes.fr (J.-P.A.); yann.guitton@oniris-nantes.fr (Y.G.) \\ 4 Faculté de Médicine de Nantes, Centre Hospitalo-Universitaire Hôtel-Dieu (CHU), 44093 Nantes, France; \\ arnaud.legrand@chu-nantes.fr (A.L.); cecile.boscher@chu-nantes.fr (C.B.) \\ 5 European Milk Bank Association (EMBA), 20126 Milan, Italy \\ * Correspondence: Marie-Cecile.Alexandre-Gouabau@univ-nantes.fr; \\ Tel.: +33-(0)2-53-48-20-12; Fax: +33-(0)2-53-48-20-03 \\ + These authors contributed equally to this work.
}

Received: 11 December 2017; Accepted: 12 January 2018; Published: 31 January 2018

\begin{abstract}
Human milk is recommended for feeding preterm infants. The current pilot study aims to determine whether breast-milk lipidome had any impact on the early growth-pattern of preterm infants fed their own mother's milk. A prospective-monocentric-observational birth-cohort was established, enrolling 138 preterm infants, who received their own mother's breast-milk throughout hospital stay. All infants were ranked according to the change in weight Z-score between birth and hospital discharge. Then, we selected infants who experienced "slower" $(n=15,-1.54 \pm 0.42$ $Z$-score) or "faster" ( $n=11,-0.48 \pm 0.19 \mathrm{Z}$-score) growth; as expected, although groups did not differ regarding gestational age, birth weight $Z$-score was lower in the "faster-growth" group $(0.56 \pm 0.72$ vs. $-1.59 \pm 0.96)$. Liquid chromatography-mass spectrometry lipidomic signatures combined with multivariate analyses made it possible to identify breast-milk lipid species that allowed clear-cut discrimination between groups. Validation of the selected biomarkers was performed using multidimensional statistical, false-discovery-rate and ROC (Receiver Operating Characteristic) tools. Breast-milk associated with faster growth contained more medium-chain saturated fatty acid and sphingomyelin, dihomo- $\gamma$-linolenic acid (DGLA)-containing phosphethanolamine, and less oleic acid-containing triglyceride and DGLA-oxylipin. The ability of such biomarkers to predict early-growth was validated in presence of confounding clinical factors but remains to be ascertained in larger cohort studies.
\end{abstract}

Keywords: breast milk lipidome; preterm infant; growth trajectory 


\section{Introduction}

A large body of epidemiologic evidence supports the short- and long-term benefit of breastfeeding in healthy term infants [1]. The World Health Organization (WHO) therefore recommends exclusive breastfeeding for the first six months of life [2]. Due to their tremendous growth rate, contrasting with the immaturity of their gastrointestinal system, most very preterm infants (born before 32 weeks of gestation) require intravenous nutrition for the first few weeks of life. As intravenous nutrition exposes to a high risk of sepsis, metabolic and hepatic complications, weaning preterm infants of intravenous nutrition is, however, a top priority and maternal milk feeding is strongly recommended in preterm infants as well [3,4]. When own mother's milk is not available, the WHO and the American Academy of Pediatrics [5] recommend the use of donated breast milk, issued from a human milk bank, as an alternative [6-8]. In particular, feeding preterm infants with human milk has been shown to be associated with: (i) a dramatic reduction in the risk of developing prematurity-related morbidities [9], including necrotizing enterocolitis [10-12] and serious infection (sepsis) [7]; (ii) improved feeding tolerance and, in turn, faster advancement of enteral feeds [10,13]; and (iii) improved neurodevelopment $[10,14]$. Moreover, a few randomized controlled trials suggest breast milk might reduce the incidence of atherosclerosis in adolescents born preterm [15]. Breast milk alone, however, due to its relatively low protein and energy content, cannot cover the tremendous needs of preterm infants, and exclusive breastfeeding is often associated with extra-uterine growth restriction (EUGR) $[14,16]$. As impaired initial growth could have severe consequences since preterm birth per se is a risk factor for developmental delay $[17,18]$, the European Society for Paediatric Gastroenterology Hepatology and Nutrition (EPSGHAN) committee on nutrition recommends human milk fortification for preterm infants [19]. Notwithstanding, a large range of variation is still observed regarding growth during hospital stay [20] even among preterm infants receiving protein-fortified human milk. Literature reports large inter-subject variations in the composition of expressed own mother's milk [21]. Indeed, the fat composition can be directly impacted by numerous factors, including maternal diet [22,23], body mass index (BMI) [24], parity [25], or stage of lactation [26,27]. Regarding gestational age, it has been reported to impact total milk fat content only in the first stage of lactation [28,29]. Milk lipid supplies not only $45-55 \%$ of the total energy requirement of a healthy infant [30], but also building blocks for tissue growth. The effects of milk fatty acids and phospholipids on neurodevelopment have been widely studied [30-32]. However, there are scarce data on the potential health benefits of specific lipid components of human milk [30], specifically on preterm infants. Although metabolomics and lipidomics seem to be a promising approach in neonatology $[33,34]$ to explore the broad range of concentrations of various components in small samples of biological materials [35], only a small number of clinical applications have appeared in literature [36-38]. Furthermore, to the best of our knowledge, no previous study has explored in depth the relationships between lipid components in human milk and the early growth of preterm infants during their hospital stay. To fill this gap, the current study aims at shedding light on the relationships between breast milk lipidome and growth pattern of preterm infants nourished by their own mother's milk. In the present pilot study, we chose to select two groups of preterm infants, presenting very different growth trajectories during hospital stay, and selected within the ongoing LACTACOL birth cohort (ClinicalTrials.gov Identifier: NCT01493063, acronyme for the clinical study titled "Impact of Breast Milk on the Neurodevelopment of Preterm Newborns"). The aim of the present work therefore was: (i) to assess lipidome in the breast milk received by preterm infants during their first weeks of life; (ii) to evaluate the association between breast milk lipidome and the weight gain of infants between birth and time of discharge, by using multivariate statistical tools that accurately discriminate the two groups of preterm infants; and (iii) to identify a few breast milk lipid species and evaluate their predictive ability on the postnatal weight growth trajectory of the preterm infants, taking into account confounding clinical factors. 


\section{Materials and Methods}

\subsection{Study Design and Population}

The present pilot study was an ancillary study conducted on sub-groups of infants selected among infants enrolled in the mono-centric prospective population-based LACTACOL birth cohort (registered at www.clinicaltrails.gov as NCT01493063) of preterm infant-mother dyads recruited from October 2011 to March 2016. The main objective of the LACTACOL cohort was to explore the impact of the protein content of breast milk provided to preterm infants during hospital stay on neurodevelopment at 2 years of age. A written consent was obtained from all participants at enrollment. One hundred thirty-eight infants born between 26 and 36 weeks of gestational age, with no major congenital disease except prematurity, were included, for a total of 118 mothers finally enrolled in the LACTACOL cohort (Figure 1). Necrotizing enterocolitis or retinopathy of prematurity were exclusion criteria. The development of comorbidities was defined as any of the following outcomes: intraventricular hemorrhage (IVH), defined as IVH associated with ventricular dilatation (grade III), cystic periventricular leukomalacia (cPVL) and ventricular dilatation, and/or severe bronchopulmonary dysplasia (BPD), defined as the administration of oxygen for at least 28 days plus the need for $30 \%$ or more oxygen and/or mechanical ventilator support or continuous positive airway pressure at 36 weeks' postmenstrual age [39]. As reported in Table 1, none of the infants enrolled in the present pilot study presented any evidence of severe neonatal morbidity.

Table 1. Maternal and preterm infants' characteristics.

\begin{tabular}{|c|c|c|c|}
\hline & "Slower" Growth Rate & "Faster" Growth Rate & $p$-Value \\
\hline Maternal Characteristics & 11 & 11 & \\
\hline Age & $30.00 \pm 4.12(26.00 ; 33.00)$ & $29.00 \pm 4.52(25.00 ; 35.00)$ & 0.908 \\
\hline BMI before gestation & $24.00 \pm 5.11(20.83 ; 30.80)$ & $22.32 \pm 5.26(19.14 ; 28.91)$ & 0.789 \\
\hline Infants characteristics at birth & 15 (10 males and 5 females) & 11 ( 7 males and 4 females) & \\
\hline \multicolumn{4}{|l|}{ Neonatal Morbidity ( $\mathrm{N}^{\circ}$ of events) } \\
\hline Grade III IVH & 0 & 0 & \\
\hline Cystic PVL & 0 & 0 & \\
\hline Severe BPD & 0 & 0 & \\
\hline Severe ROP & 0 & 0 & \\
\hline Severe NEC & 0 & 0 & \\
\hline Gestational age $(w)$ & $30.00 \pm 1.68(29.00 ; 32.00)$ & $31.00 \pm 1.37(30.0 ; 32.00)$ & 0.288 \\
\hline Hospital stay $(\mathrm{d})$ & $49.50 \pm 4.21(36.75 ; 54.75)$ & $51.50 \pm 3.16(37.25 ; 56.25)$ & 0.849 \\
\hline Birth weight (kg) & $1.605 \pm 0.211(1.465 ; 1.705)$ & $1.200 \pm 0.293(1.020 ; 1.445)$ & 0.005 \\
\hline Birth length $(\mathrm{cm})$ & $41.20 \pm 1.38(39.00 ; 41.60)$ & $38.00 \pm 1.84(37.00 ; 40.00)$ & 0.004 \\
\hline Birth head circumference $(\mathrm{cm})$ & $28.00 \pm 1.53(27.00 ; 29.00)$ & $26.20 \pm 2.07(25.505 ; 28.20)$ & 0.202 \\
\hline Birth weight Z-score (SD) & $0.564 \pm 0.718(-0.290 ; 0.842)$ & $-1.592 \pm 0.958(-2.079 ;-0.571)$ & 0.000 \\
\hline Birth length Z-score (SD) & $0.210 \pm 0.725(-0.522 ; 0.746)$ & $-0.793 \pm 0.939(-2.245 ;-0.129)$ & 0.003 \\
\hline Birth head circumference Z-score (SD) & $-0.036 \pm 0.795(-0.686 ; 0.386)$ & $-1.528 \pm 1.212(-1.651 ;-0.128)$ & 0.015 \\
\hline BMI at birth $\left(\mathrm{kg} / \mathrm{m}^{2}\right)$ & $9.455 \pm 0.857(8.843 ; 9.900)$ & $7.694 \pm 1.573(7.139 ; 9.884)$ & 0.161 \\
\hline Discharge weight (kg) & $2.565 \pm 0.270(2.355 ; 2.720)$ & $2.340 \pm 0.320(2.029 ; 2.520)$ & 0.041 \\
\hline Discharge length $(\mathrm{cm})$ & $45.00 \pm 1.529(44.10 ; 46.00)$ & $44.00 \pm 2.543(41.00 ; 45.50)$ & 0.219 \\
\hline Discharge head circumference $(\mathrm{cm})$ & $33.00 \pm 1.412(32.50 ; 34.00)$ & $33.50 \pm 1.511(32.00 ; 34.00)$ & 0.787 \\
\hline Discharge weight Z-score (SD) & $-1.142 \pm 0.682(-1.552 ;-0.953)$ & $-1.878 \pm 0.857(-2.264 ;-1.127)$ & 0.146 \\
\hline Discharge length Z-score (SD) & $-1.800 \pm 0.713(-2.242 ;-1.251)$ & $-2.349 \pm 1.054(-2.803 ;-1.096)$ & 0.466 \\
\hline Discharge head circumference Z-score (SD) & $-0.681 \pm 0.775(-1.184 ; 0.301)$ & $-0.216 \pm 0.754(-1.010 ; 0.1074)$ & 0.655 \\
\hline BMI at Discharge $\left(\mathrm{kg} / \mathrm{m}^{2}\right)$ & $12.67 \pm 0.955(11.78 ; 13.36)$ & $11.98 \pm 0.485(11.66 ; 12.28)$ & 0.047 \\
\hline $\begin{array}{l}\text { Difference between discharge and birth } \\
\text { weight } Z \text {-score (SD) }\end{array}$ & $-1.538 \pm 0.417(-1.953 ;-1.230)$ & $-0.479 \pm 0.189(-0.668 ;-0.294)$ & $<0.001$ \\
\hline $\begin{array}{c}\text { Difference between discharge and birth } \\
\text { length Z-score (SD) }\end{array}$ & $-2.010 \pm 0.752(-2.474 ;-1.278)$ & $-0.940 \pm 0.723(-1.822 ;-0.343)$ & 0.015 \\
\hline $\begin{array}{l}\text { Difference between discharge and birth } \\
\text { head circumference Z-score (SD) }\end{array}$ & $-0.113 \pm 0.887(-1.351 ; 0.258)$ & $0.762 \pm 1.122(-0.248 ; 1.401)$ & 0.017 \\
\hline
\end{tabular}

Abbreviations: BPD, bronchopulmonary dysplasia; IPH, intraparenchymal hemorrhage; IVH, intraventricular hemorrhage; NEC, necrotizing enterocolitis; PVL, periventricular leukomalacia; ROP, retinopathy of prematurity. Severe bronchopulmonary dysplasia (BPD), defined as the administration of oxygen for at least 28 days plus the need for $30 \%$ or more oxygen and/or mechanical ventilator support or continuous positive airway pressure at 36 weeks' postmenstrual age [39]. SD: standard deviation. Values are medians and $25 \%$ and $75 \%$ percentiles. $p$ values for comparison between "faster" and "slower" growth groups were derived by using Mann-Whitney $U$ test. Characteristics in bold font presented a corrected $p$-value $<0.05$ between the two infant groups. 


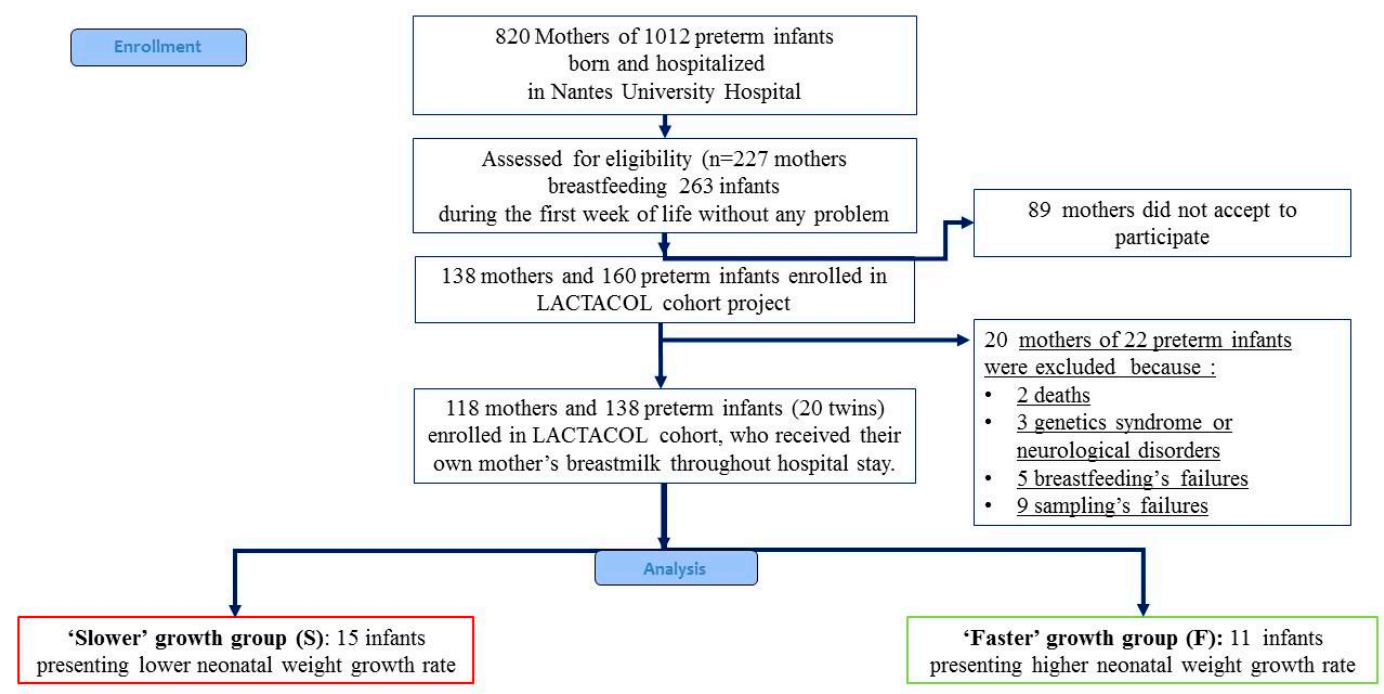

Figure 1. Flowchart of infants enrolled in the ancillary study of the mono-centric prospective population-based LACTACOL. (ClinicalTrials.gov Identifier: NCT01493063, acronyme for "Impact of Breast Milk on the Neurodevelopment of Preterm Newborns").

Infants admitted to the Neonatal Intensive Care Unit at Nantes University Hospital were eligible if they received human milk as their sole feeding for more than 28 days. Clinical characteristics were collected both on mothers and infants, including: maternal age, educational level, pre-gravid BMI, adverse events during pregnancy and delivery, infants' gestational age, birth weight and head circumference, growth trajectory through hospital discharge, and events during hospital stay in neonatology. Parenteral nutritional supply was recorded daily, as well as enteral intake: volume of milk delivered per feeding session, fortifiers used and fortification level. The fortification followed, as far as possible, the EPSGHAN recommendations [19] regarding mean daily energy (i.e., 110-135 kcal/kg body weight/day) and macronutrient intake: $3.5-4.0 \mathrm{~g} / \mathrm{kg}$ body weight/day for protein (for babies with 1-1.8 kg body weight); 4.8-6.6 g/ $\mathrm{kg}$ body weight/day for lipid; and 11.6-13.2 g/ kg body weight/day for carbohydrate. Human milk fortification was performed using Eoprotine ${ }^{\circledR}$ (Milupa, Domdidier, Suisse) and FortiPré ${ }^{\circledR}$ (Guigoz, Noisiel, France), for protein and carbohydrate; Liquigen ${ }^{\circledR}$ (Nutricia, Saint-Ouen, France) for lipid; and Dextrin maltose, for carbohydrate. Energy and protein contents in preterm standard formula were $72 \mathrm{kcal} / 100 \mathrm{~mL}$ and $2 \mathrm{~g} / 100 \mathrm{~mL}$, respectively [40]. By taking into account native own mother's milk macro-nutriments contents (measured by MIRIS human milk analyzer (Miris $A B^{\circledR}$, Uppsala, Sweden) analysis, Section 2.4) and routine fortification, the mean total enteral intake at 3 weeks of age, was: $2.48 \pm 0.16$ in the "faster growth" group, vs. $2.49 \pm 0.12 \mathrm{~g} / \mathrm{kg} /$ day in the "slower growth" group ( $p$-value $=0.69)$ for protein; $6.76 \pm 0.56 \mathrm{vs.} 5.48 \pm 0.45 \mathrm{~g} / \mathrm{kg} /$ day $(p$-value $=0.08)$ for lipid; and $13.08 \pm 0.59$ vs. $14.14 \pm 0.49 \mathrm{~g} / \mathrm{kg}$ body weight $/ \mathrm{day}(p$-value $=0.31)$ for carbohydrate. The mean energy intake was: $125.8 \pm 6.07 \mathrm{vs.} 118.1 \pm 4.99 \mathrm{kcal} / \mathrm{kg}$ body weight/day ( $p$-value $=0.17$ ). These values were reasonably close to that of EPSGHAN guidelines except for protein intake (which was $28 \%$ below recommended intake) whereas total energy intake was consistent with guidelines in both groups of infants. Preterm infants received parenteral nutrition and minimal enteral feeding, predominantly with expressed breast milk, for a minimum of two weeks.

\subsection{Ranking Infants According to Early Growth Trajectory}

Body weight was measured weekly from birth to discharge (accuracy of $0.1 \mathrm{~g}$ ). Weight Z-score was calculated using the Lambda Mu Sigma (LMS) method [41] and Olsen's preterm infant growth chart [42] was applied with respect to birth and discharge measurements. After completion of the cohort, for the specific purpose of the current pilot study, infants enrolled in LACTACOL cohort were ranked according to their growth trajectory during hospital stay. Weight gain during hospitalization 
was assessed as the change in weight Z-score (expressed in units of Standard Deviation (SD) using the SD of the term category as the benchmark) between birth and hospital discharge and all infants were then ranked, according to this difference in weight Z-score. We then selected two groups of infants who belonged either to the first or to the last terciles of growth rate in our population of 138 enrolled preterm babies (i.e., a difference between discharge and birth weight Z-score greater than -0.56 or lower than -1.06 , respectively); those 2 groups of infants are termed infants with "faster growth" or "slower growth" in the following (Figure 1). The infants with "faster growth" $(n=11$ infants ( 7 boys and 4 girls) presented a difference between discharge and birth weight Z-score of: $-0.479 \pm 0.189(-0.668 ;-0.294)$ SD (median and $25 \%$ and $75 \%$ percentiles). The infants with "slower growth" ( $n=15$ infants (10 boys and 5 girls) presented a difference between discharge and birth weight Z-score of: $-1.538 \pm 0.417(-1.953 ;-1.230)$ SD (median and $25 \%$ and $75 \%$ percentiles). Moreover, in the selection of the infants, we had two others constraints: the availability of sufficient own mother's milk samplings from week 2 to week 7 of lactation, and of infant serum (results not shown in the present work). Two sets of twins belonged to the "slower" growth group and two others sets of twins followed opposite trajectories regarding their weight Z-score difference between birth and hospital discharge, i.e., one set of twins belonged to the "faster" growth group, and the other belonged to the "slower" growth group. Clinical characteristics of mother-infant dyads are summarized in Table 1. Although gestational age (30-31 weeks) and length of hospital stay (49-51 days) did not differ between the groups, the group of infants with "faster" growth had a $25 \%$ lower birth weight (i.e., $1.200 \pm 0.293 \mathrm{~kg}$ vs. $1.605 \pm 0.211 \mathrm{~kg}$ ) combined with a $69 \%$ greater gain in weight Z-score between birth and discharge. This negative correlation between birth weight and weight Z-score at time of discharge has long been known, and was previously reported in the large Loire Infant Follow-up Team (LIFT) cohort of 2277 preterm infants by our team [40] and in another cohort [43].

\subsection{Ethics}

This research study, referenced BRD/11/02-Y at Nantes University Hospital, was approved, on 28 February 2011, by the National Data Protection Authority (Commission Nationale de l'Informatique et des Libertés, No. 8911009) and, on 19 July 2011, by the appropriate ethics Committee for the Protection of People Participating in Biomedical Research (CPP-Ouest I (Tours, France), reference CPP RCB-2011-AOO292-39). The LACTACOL cohort was registered at www.clinicaltrials.gov under \# NCT01493063. The current data were obtained in the corresponding ancillary study $\mathrm{N}^{\circ} 3$ with the following outcome i.e., to assess the relationship between the composition of breast milk (lipidome in the present study) and preterm infant's growth trajectory during the first few weeks of life. The milk biobank was approved by the Committee for the Protection of Persons in medical research (approval was granted 24 June 2010, reference CPP CB-2010-03). Parents received oral and written information in the maternity ward or neonatal unit, lactation support and training on proper sample collection from the study lactation consultant. A written consent was obtained from all parents at enrolment.

\subsection{Human Milk Collection and Targeted Fatty Acid Analysis}

Weekly breast milk expression was performed manually by mothers at home, using a Medela Manual Breast pump (Medela Inc., Etampes, France). Representative 24-h mature milk samples were obtained by pooling breast milk sampled from 5 to 6 bottles brought daily to the Milk Bank of the Nantes University Hospital. The whole milk pool was homogenized with a disruptor (Polytron, Lucerne, Switzerland) and kept frozen at $-80{ }^{\circ} \mathrm{C}$ until analysis. Total milk fat was measured using the MIRIS ${ }^{\circledR}$ human milk analyzer (Miris $\mathrm{AB}^{\circledR}$, Uppsala, Sweden), based on mid-infrared methodology [44]. The modified liquid-liquid extraction method of Bligh-Dyer [45] was used to extract lipophilic metabolites. Two lipid analyses were achieved: a first targeted analysis of total fatty acids and a second untargeted lipidomic profiling. Total fatty acids were analyzed by gas chromatography using an Agilent Technologies $7890 A^{\circledR}$ instrument (Perkin Elmer, Villebon-sur-Yvette, France), 
following trans-esterification [46]. See Supplementary Materials online for detailed information about biochemical analysis and materials used.

\subsection{Breast Milk Liquid Chromatography-High-Resolution-Mass Spectrometry (LC-HRMS)-Based Lipidomic Profiling}

Following Bligh-Dyer extraction, the organic layers were dried and subsequently reconstituted in acetonitrile-isopropanol-water (ACN:IPA: $\mathrm{H}_{2} \mathrm{O}$ 65:30:5, v/v/v). A 1200 infinity series ${ }^{\circledR}$ high performance liquid chromatography (HPLC) system (Agilent Technologies, Santa Clara, CA, USA) coupled to an Exactive Orbitrap ${ }^{\circledR}$ mass spectrometer (Thermo Fisher Scientific, Bremen, Germany) equipped with a heated electrospray (H-ESI II) source (operating in polarity switch mode) was used for lipid profiling. The full instrument calibration was performed using a MSCAL6 ProteoMassT LTQ/FT-Hybrid ESI Pos/Neg ${ }^{\circledR}$ (Sigma-Aldrich, St. Louis, MO, USA). Xcalibur 2.2 ${ }^{\circledR}$ (Thermo Fisher Scientific, San Jose, CA, USA) was used for data acquisition and analysis. Lipid species separation was performed on a reverse phase $\mathrm{CSH}^{\circledR} \mathrm{C}_{18}\left(100 \times 2.1 \mathrm{~mm}^{2}\right.$ i.d., $1.7 \mu \mathrm{m}$ particle size) column (Waters Corporation, Milford, MA, USA) using ACN: $\mathrm{H}_{2} \mathrm{O}(60: 40)$ and IPA:ACN: $\mathrm{H}_{2} \mathrm{O}(88: 10: 2)$ as solvent $\mathrm{A}$ and $\mathrm{B}$, respectively; both containing $10 \mathrm{mM}$ ammonium acetate and $0.1 \%$ acetic acid [47]. The precision associated with sample preparation and LC-HRMS measurement was determined based on a quality control (QC) consisting of a pool of 10 mothers' milk provided by the milk bank of Nantes Hospital Center. Summary assay procedures have been detailed in Supplementary Material.

\subsection{Data Analysis and Lipid Species Characterization}

LC-ESI (positive/negative) HRMS raw data files were initially preprocessed with Xcalibur $2.2^{\circledR}$ (Thermo Fisher Scientific, San Jose, CA, USA), converted to the ( ${ }^{*}$.mzXML) cross-platform open file format, using MSConvert ${ }^{\circledR}$ [48], and processed using Workflow4Metabolomics ${ }^{\circledR}$ (W4M) (http: //workflow4metabolomics.org) [49]. Lipidomic data were extracted using: (i) pre-processing with the open-source $\mathrm{XCMS}^{\circledR}$ [50] within W4M [49], for nonlinear retention time alignment and for automatic integration and extraction of the peak intensities for each detected features (ions of given mass-to charge ratio and retention time $[\mathrm{m} / z ; \mathrm{RT}])$, combined to CAMERA ${ }^{\circledR}[51]$, for annotation of isotopes and adducts; and (ii) normalization of intra- and inter-batch effects by fitting linear or local polynomial regression models to QC samples [52]. The resulting XCMS $[m / z ; R T]$ features for each sample was subsequently manually sorted out according to their quality of integration and filtered by a $30 \%$ relative SD cutoff within the repeated pooled QC injections (see Dunn and co-workers' recommendations [53]). Thereafter, accurate mass measurement of each putative metabolite was submitted to LIPID Metabolites and Pathways Strategy (LipidMaps ${ }^{\circledR}$, www.lipidmaps.org) annotation. Moreover, the use of all ion fragmentation, when reverse phase chromatography was applied, helped us identify the proposed lipids by examination of the (pseudo) tandem mass spectrometry spectrum generated [47], combined with the use of an in-house reference databank [54].

\subsection{Statistical Analyses}

Statistical analyses were carried out using GraphPad Prism ${ }^{\circledR}$ software version 6.00 (La Joya, CA, USA), SIMCA $P^{\circledR}$ version 13 (Umetrics AB, Malmö, Sweden) and R version 3.2.5 (R Development Core Team, 2013, R Foundation for Statistical Computing, Vienna, Austria; http:/ /www.R-project.org). For all data analyses, the significance level $(\alpha)$ was set to $5 \%$, and $10 \%$ for Multiple Linear Regression. Multivariate statistical models were applied on pre-processed QC-filtered lipidomic mother $x$ time (rows) by $[\mathrm{m} / \mathrm{z} ; \mathrm{RT}]$ features (columns) data matrix considering the a priori structure into "faster" vs. "slower" infants' growth groups. Lipidomic features were column-wise centered and scaled with a Log Pareto scaling [55]. A statistical workflow (Figure 2) was set up to: (i) select the most reliable lactation points; (ii) identify the lipid biomarkers providing a clear separation between the two infant postnatal growth subgroups; (iii) check the selected biomarkers predictive ability; and (iv) confront them to the various confounding clinical variables. 


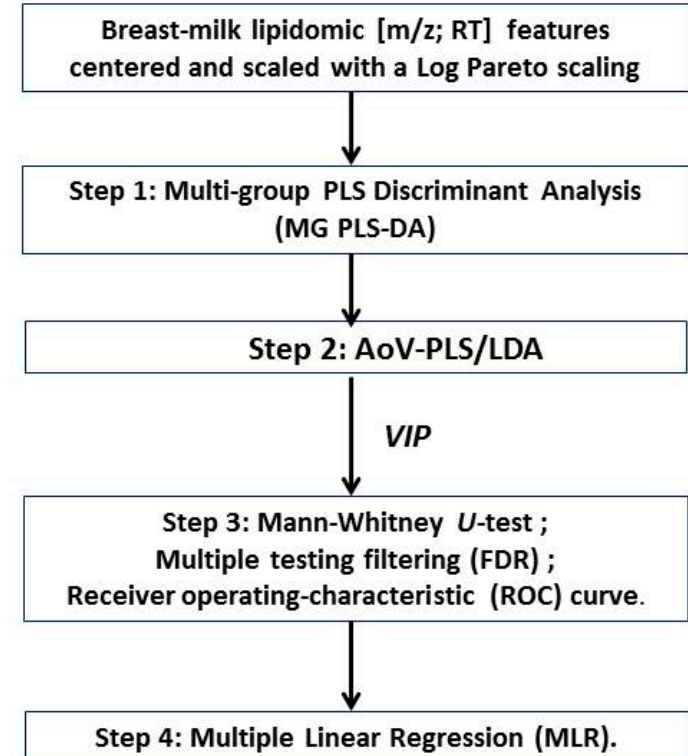

To select the most reliable lactation points

To identify the lipid biomarkers providing a clear separation between the two infant postnatal growth subgroups: 'Faster' versus 'Slower' early growth.

To check the selected biomarkers predictive ability

To confront the selected biomarkers to the various confound clinical variables

Figure 2. Statistical workflow applied on breast-milk Liquid Chromatography-High-Resolution-Mass Spectrometry profiles obtained in positive and negative ionization mode.

Step 1: Selection of the most reliable lactation points. Multi-group PLS Discriminant Analysis (MG PLS-DA) [56] was performed to explain the a priori infant growth trajectory taking into account the longitudinal character of the data (weekly measurements) as groups among the rows (multigroup package in R) [57]. As a matter of fact, MG PLS-DA model revealed the time lactation points presenting the best differentiation between the two groups ("faster" vs. "slower" infant growth). Thereafter, only the most discriminant time lactation points were considered in the subsequent analyses and the significance of the growth factor was assessed. To cope with multi-colinearity inherent in metabolomics data [58,59], the Analysis of Variance-PLS (AoV-PLS) procedure proposed by El Ghaziri et al. [60] was applied.

Step 2: Identification of the lipid species biomarkers. AoV-PLS aimed at: (i) exploring how "faster" vs. "slower" preterm infants' growth structure was explained by milk lipidomic signatures; and (ii) pinpointing the most discriminant features related to the infants' growth pattern during hospital stay. This selection was performed on the basis of the variables of importance (for the milk clustering) indices (VIP > 1.0) [61] reflecting the contribution of each variable $([\mathrm{m} / z ; \mathrm{RT}]$ feature) to the separation of the two infant groups. The appropriate number of components retained for the AoV-PLS model was chosen on the basis of the RMSEP (root mean square error of prediction) value obtained with a leave-one-out cross-validation procedure. In a subsequent stage, the selected AoV-PLS components were subjected to a Fisher's linear discriminant analysis (LDA) to assess the significance of this model with respect with the two a priori groups ("faster" vs. "slower" infant growth) (function linDA of the DiscriMiner package in R [62]).

Step 3: Validation of the predictive ability of the selected biomarkers. To determine the more robust putative biomarkers of infant growth during hospital stay, lipid species that had been selected on the basis of AoV-PLS/LDA VIP indices in a multivariate scope were submitted to: (i) a subsequent univariate Mann-Whitney U-test; (ii) multiple testing filtering (FDR); and (iii) receiver operating-characteristic (ROC) curve (GraphPad Prism $\left.{ }^{\circledR}\right)$. The parameter associated to the area under the curve (AUC) was set at 0.5 while the $\alpha$-threshold was set at 0.05 .

Step 4: Introduction of confounding clinical variables. Finally, confounding variables encompassing maternal and infant clinical data were introduced together with every selected putative biomarker to validate its reliability. The association between selected breast milk lipid species and 
child's growth in terms of weight gain during hospital stay (delta Z-score) were investigated by means of Multiple Linear Regression (MLR), taking into account these confounding variables.

\section{Results}

\subsection{A Distinct Breast Milk Lipidomic Signature Is Associated with Infant Growth Rate during Hospital Stay}

Selected features of lipidomic LC-HRMS $\left(\mathrm{ESI}^{+} / \mathrm{ESI}^{-}\right)$profiles performed on breast milk samples from Week 2 to Week 7 of lactation were processed with MG PLS-DA (Step 1).

On the corresponding score plots obtained in positive (Figure 3) and negative (Figure S1) ionization mode (3451 and 903 features respectively, 118 observations), the milk samples associated with the two groups ("faster" vs. "slower" growth) are plotted separately for each weekly sampling time point (i.e., Weeks 2 to 7). The first three sampling points at Weeks 2, 3 and 4 (i.e., from the 12th to the 24th day (median values)) allowed the best separation between the two groups of milks. This result led us to further restrict the multivariate analysis to data from samples obtained between Week 2 and Week 4 .

\section{MG-PLS-DA score plots}

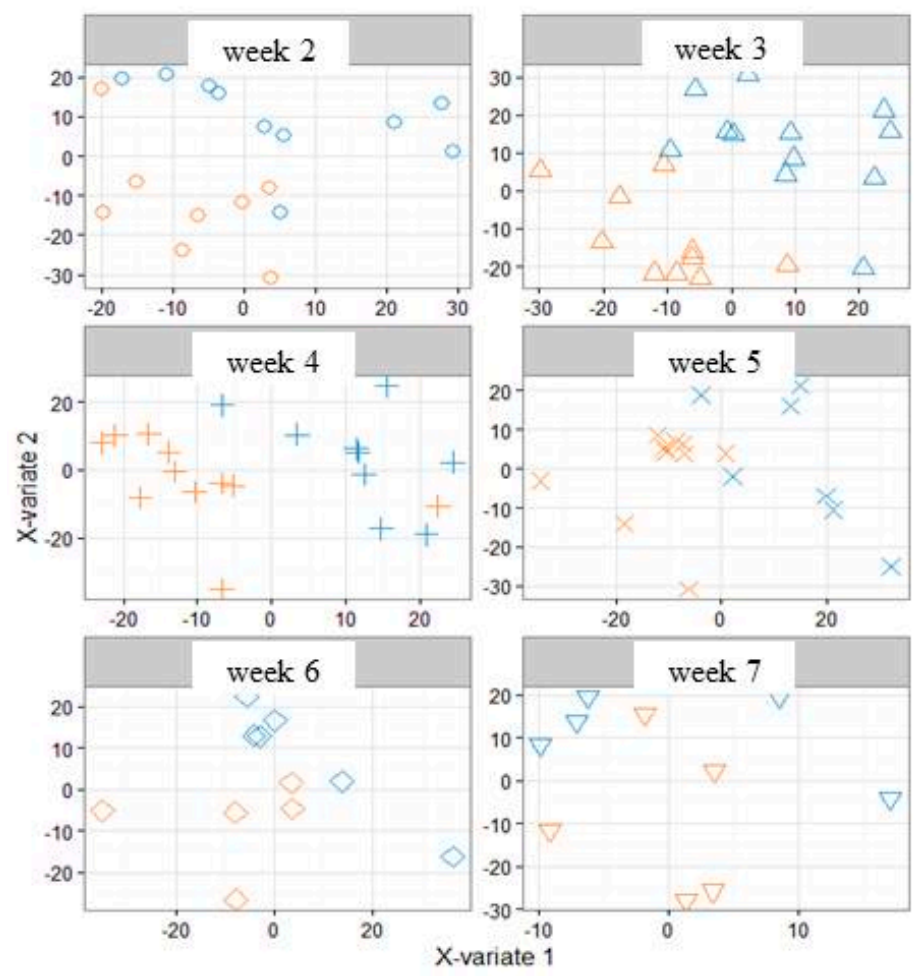

Figure 3. Multi-group PLS-DA score plots based on the LC-ESI ${ }^{+}-H R M S$ profiles (3451 features, 118 milks) obtained on human preterm milk. Representation of the individuals: milk provided to preterm infants who experienced "faster" (orange) or "slower" (blue) growth from Week 2 to Week 7 of lactation. MB-PLS-DA score plots: $\bigcirc$ Week 2; $\Delta$ Week $3 ;+$ Week $4 ; \times$ Week $5 ; \diamond$ Week $6 ; \nabla$ Week 7.

AoV-PLS (Step 2) was applied separately on the LC-HRMS (ESI ${ }^{+} / \mathrm{ESI}^{-}$) to assess the association between the metabolites and the a priori grouping structure ("faster" vs. "slower" growth). The score plots clearly highlight the separation between breast milk lipidotypes associated with "faster" or "slower" infant growth in both positive (Figure 4a) and negative (Figure S2a) ionization modes. Interestingly, the breast milk lipidomic profiles, corresponding to two sets of twins with a concordant low growth rate, were plotted in the "slower growth" milk cluster. The lipidomic profiles of the breast milk provided to two sets of twins with discordant weight Z-score difference, one corresponding to 
"faster" ( -0.668 and -0.479 SD) and the other to "slower" (-1.23 and -1.53 SD) growth, were found to be in an intermediate location between the two lipidotypes (depicted with blue symbols in Figure 4a and Figure S2). Then, the selected appropriate components of AoV-PLSs (for both ionization modes) were subjected to a Fisher's linear discriminant analysis (LDA) to test the significance of growth factor.

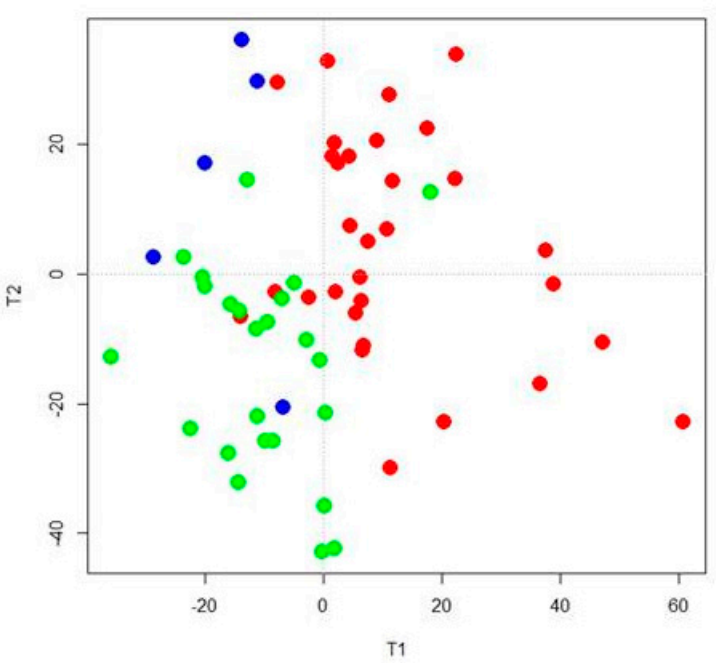

(a)

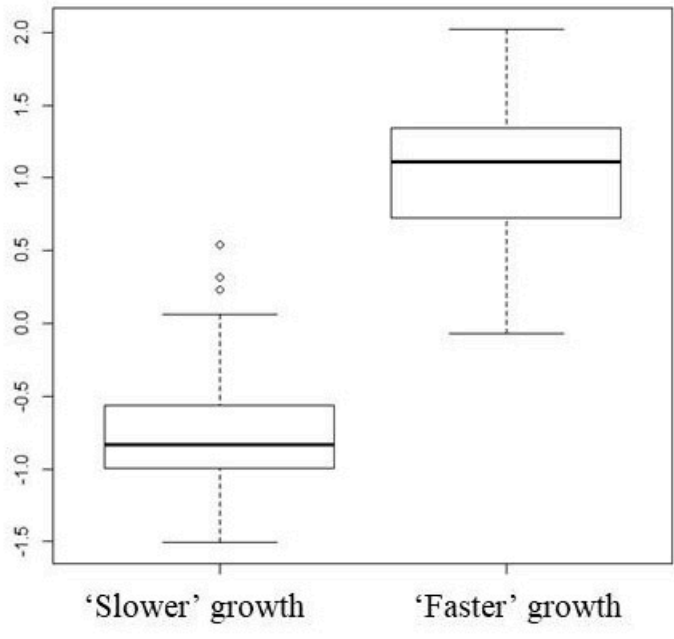

(b)

Figure 4. AoV-PLS and LDA models, based on the LC-ESI ${ }^{+}-H R M S$ profiles of human preterm milk, on the factor weight $Z$-score (discharge-birth): AoV-PLS score plot with $45 \%$ of variance (R2Y = 38\%) on: components 1-2 (a); and LDA (built on 10 components of AoV-PLS) with a $p$-value $=0)(\mathbf{b})$. Breast milk provided to preterm infants who experienced "faster" (green) or "slower" (red) growth and to twin infants with discordant growth rate, one with high growth rate and one with low growth rate, (blue).

The correlation ratio associated with the LDA canonical variable was equal to $71 \%$, with respect to the positive mode (Figure $4 \mathrm{~b}$ ), and $61 \%$ with respect to the negative mode (Figure S2b), while their cross-validation error rates were both equal to $7.14 \%$. The most discriminant features associated with infant growth during hospital stay corresponded to a cluster of 1006 (respectively, 256) VIP-based lipid species, in the positive (respectively, negative) ionization mode.

\subsection{Characterization of Preterm Breast Milk Lipidotypes in the First Month of Lactation}

Considering the targeted analysis of total fatty acids, milk provided to the "faster" growth group contained more total fat $(4.75 \mathrm{~g} / 100 \mathrm{~mL})$ than the milk provided to infants with a slower growth rate (3.55 g/100 mL) from Week 2 to Week 4 (Table 2) (Table S1, for each sampling time, W2, W3 and W4 of lactation). This is, mainly due to a higher abundance of total saturated fatty acids (SAT) (free and triglycerides- and phospholipids-bound fatty acids) and particularly, medium-chain SAT (MCSAT). In contrast, total mono-unsaturated fatty acids (MUFA), the second most abundant class of milk fatty acids, were lower in the "faster growth" group than in the "slower" group, essentially due to lower oleic acid content. Milk provided to infants who experienced "faster growth" contained more overall n-3 long-chain PUFA, such as docosahexanoic acid and its precursors (eicosapentaenoic and docosapentaenoic acids). Finally, the essential FA content (i.e., linoleic and $\alpha$-linolenic acids), was similar in both groups during this W2-W4 period. 
Table 2. Concentration levels of total fatty acids (free and triglycerides- and phospholipids-bound) in breast milk provided to preterm infants with "faster" or "slower" growth during the W2-W4 lactation period.

\begin{tabular}{|c|c|c|c|c|}
\hline \multirow[b]{2}{*}{ Fatty Acids (\%) } & \multicolumn{2}{|c|}{$\mathrm{W} 2$ to $\mathrm{W} 4$} & \multirow{2}{*}{$\begin{array}{l}\text { Mann-Whitney } \\
p \text {-Value from } \\
\text { W2 to W4 }\end{array}$} & \multirow{2}{*}{$\begin{array}{l}\text { FDR Corrected } \\
q \text {-Value from } \\
\text { W2 to W4 }\end{array}$} \\
\hline & $\begin{array}{l}\text { "Slower" Growth } \\
(n=38)\end{array}$ & $\begin{array}{c}\text { "Faster" Growth } \\
(n=29)\end{array}$ & & \\
\hline $8: 0$ & $0.176(0.151-0.211)$ & $0.198(0.157-0.236)$ & 0.201 & 0.183 \\
\hline $10: 0$ & $1.654(1.512-1.911)$ & $1.791(1.591-2.082)$ & 0.101 & 0.132 \\
\hline $12: 0$ & $6.203(5.817-6.866)$ & $7.100(6.069-8.127)^{a}$ & 0.022 & 0.055 \\
\hline 14:0 & 7.049 (6.053-8.045) & $8.039(6.909-9.629)^{a}$ & 0.013 & 0.046 \\
\hline $16: 0$ & $23.19(19.48-24.84)$ & $23.15(21.21-24.84)$ & 0.677 & 0.353 \\
\hline $18: 0$ & $6.872(6.313-7.556)$ & $6.934(5.883-7.435)$ & 0.406 & 0.279 \\
\hline $20: 0$ & $0.195(0.170-0.211)$ & $0.196(0.178-0.211)$ & 0.872 & 0.379 \\
\hline SAT & $45.74(41.97-48.51)$ & $48.08(45.81-49.54)^{\mathrm{a}}$ & 0.027 & 0.051 \\
\hline MCSAT & $8.050(7.506-8.871)$ & $8.976(7.772-10.210)^{a}$ & 0.019 & 0.051 \\
\hline $16: 1_{n-9}$ & $0.479(0.419-0.530)$ & $0.4573(0.393-0.514)$ & 0.192 & 0.183 \\
\hline $16: 1_{n-7}$ & $2.331(2.030-2.737)$ & $2.239(2.098-2.698)$ & 0.852 & 0.379 \\
\hline $17: 1_{n-7}$ & $0.222(0.175-0.247)$ & $0.228(0.190-0.261)$ & 0.310 & 0.249 \\
\hline $18: 1_{n-9}$ & $34.79(32.25-37.88)$ & $32.82(31.02-34.78)^{a}$ & 0.027 & 0.055 \\
\hline $18: 1_{n-7}$ & $1.720(1.495-1.993)$ & $1.818(1.556-2.007)$ & 0.468 & 0.287 \\
\hline $20: 1_{n-9}$ & $0.532(0.483-0.567)$ & $0.520(0.462-0.597)$ & 0.801 & 0.379 \\
\hline MUFA & $41.10(37.77-44.35)$ & $39.58(36.87-40.82)^{a}$ & 0.047 & 0.059 \\
\hline MUFA/SAT & $0.91(0.79-1.04)$ & $0.82(0.74-0.91)^{\mathrm{a}}$ & 0.037 & 0.059 \\
\hline $18: 1_{n-9}$ and $n-7$ & 36.67 (34.09-39.79) & $34.78(32.76-36.61)^{a}$ & 0.028 & 0.051 \\
\hline cis $18: 2_{n-6}$ (LA) & $9.651(8.754-12.41)$ & 8.881 (7.859-11.64) & 0.078 & 0.117 \\
\hline cis $18: 3_{n-6}$ (GLNA) & $0.107(0.086-0.133)$ & $0.099(0.078-0.125)$ & 0.370 & 0.276 \\
\hline cis $20: 2_{n-6}$ & $0.295(0.252-0.332)$ & $0.295(0.235-0.343)$ & 0.615 & 0.337 \\
\hline cis $20: 3_{n-6}$ (DGLA) & $0.349(0.317-0.443)$ & $0.404(0.317-0.456)$ & 0.429 & 0.279 \\
\hline cis $20: 4_{n-6}$ (AA) & $0.502(0.425-0.580)$ & $0.467(0.379-0.591)$ & 0.544 & 0.315 \\
\hline cis $22: 2_{n-6}$ & $0.048(0.040-0.061)$ & $0.048(0.039-0.060)$ & 0.791 & 0.379 \\
\hline cis $22: 4_{n-6}$ & $0.113(0.091-0.135)$ & $0.108(0.086-0.134)$ & 0.945 & 0.394 \\
\hline Total n-6 PUFA & $11.44(10.20-14.14)$ & $10.38(9.434-13.32)$ & 0.091 & 0.088 \\
\hline cis $18: 3_{n-3}$ (ALNA) & $0.831(0.609-1.140)$ & $0.947(0.720-1.285)$ & 0.210 & 0.183 \\
\hline cis $20: 5_{n-3}$ (EPA) & $0.058(0.042-0.077)$ & $0.076(0.061-0.092)^{b}$ & 0.006 & 0.046 \\
\hline cis $22: 5_{n-3}$ (DPA) & $0.141(0.114-0.172)$ & $0.164(0.140-0.180)^{a}$ & 0.057 & 0.098 \\
\hline cis $22: 6_{n-3}$ (DHA) & $0.320(0.220-0.390)$ & $0.383(0.316-0.477)^{a}$ & 0.013 & 0.046 \\
\hline Total n-3 PUFA & $1.598(1.411-1.976)$ & $1.881(1.466-2.213)^{a}$ & 0.058 & 0.067 \\
\hline Total PUFA & $12.96(11.74-16.40)$ & $12.29(11.15-15.65)$ & 0.201 & 0.159 \\
\hline Unsaturated/saturated fatty acid & $1.18(1.06-1.38)$ & $1.08(1.02-1.18)^{a}$ & 0.023 & 0.052 \\
\hline PUFA/SFA & $0.29(0.24-0.38)$ & $0.26(0.22-0.32)$ & 0.101 & 0.088 \\
\hline n-6/n-3 PUFA & $7.03(5.83-8.23)$ & $5.71(5.04-6.87)^{2}$ & 0.005 & 0.052 \\
\hline LC-PUFA & $2.088(1.768-2.321)$ & $2.129(1.978-2.383)$ & 0.268 & 0.200 \\
\hline Essential FA (LA + ALNA) & $10.73(9.46-13.81)$ & $9.83(8.79-13.18)$ & 0.101 & 0.088 \\
\hline LA/ALA & $10.86(9.30-15.66)$ & $9.99(8.35-11.69)^{\mathrm{a}}$ & 0.047 & 0.059 \\
\hline AA/DHA & $1.679(1.251-2.191)$ & $1.307(0.983-1.690)^{b}$ & 0.010 & 0.052 \\
\hline BCFA & $29.82(28.65-30.99)$ & $31.25(29.99-32.51)$ & 0.104 & 0.088 \\
\hline Total lipids (Miris) (g/100 mL) & $3.55(3.12-4.57)$ & $4.75(3.97-5.65)^{\mathrm{a}}$ & 0.027 & 0.052 \\
\hline
\end{tabular}

PUFA: Polyunsaturated fatty acid; AA: arachidonic acid; EPA: eicosapentaenoic acid; DHA: docosahexanoic acid; DGLA: dihomo-gamma-linolenic acid; GLNA: gamma-linolenic acid; LA: Linoleic acid; ALNA: alpha-Linolenic acid; SAT: saturated fatty acids; MCSAT: medium-chain saturated fatty acids (C8:0 to C12:0); MUFA: monounsaturated fatty acid; LC-PUFA: long-Chain PUFA (polyunsaturated fatty acid that contains at least 20 carbons); BCFA: branched-chain fatty acids (C14:0, C15:0; C17:0 and C16:0). Values (expressed as \% of total identified FA) are median and $[25 \%$ and $75 \%$ percentile] and are given for fatty acids present at $>0.05 \%$ of total fatty acids in milk. Values of $p$-values (assessed by Mann-Whitney U test) between "faster" and "slower" growth groups were reported with ${ }^{\mathrm{a}}$ or $^{\mathrm{b}}$ significantly different, $p<0.05$ or $p<0.01$, respectively; $n$ : milk samplings between Week 2 and Week 4 of lactation. Fatty acids in bold font presented a corrected $p$-value $<0.05$ and fatty acids in bold and italic font presented a corrected $p$-value between 0.05 and 0.1 , using the post hoc control of the type I error rate (False discovery Rate procedure), between the two infant groups over the entire W2-W4 lactation period.

Considering the untargeted lipidomic LC-HRMS signatures, among the 1262 features, selected as described above, 162 discriminant lipid species were annotated and are listed comprehensively in Table 3, for the overall W2-W4 lactation period, and in Table S2, for each sampling time, W2, W3 and W4 of lactation. Most of the annotated lipids were more abundant in the breast milk provided to infants with "faster" postnatal growth.

Indeed, these milks contained higher levels of medium- or long-chain sphingomyelins and ceramides [such as Cer (d18:1/24:0), SM(d18:0/12:0)], in several phosphatidylcholines, phosphatidylethanolamines or plasmalogen-derivatives containing palmitic (C16:0) or palmitoleic 
(C16:1) acid [such as PE (16:0/16:1), PE (16:1/20:0)], stearic (C18:0) or oleic (C18:1) acid [such as PC (18:0/18:1), PC (18:0/18:2) and PE (O-18:0/20:5)], dihomo- $\gamma$-linolenic acid (DGLA, C20:3) [PE (20:3/22:6), PE (22:0/20:3)], or docosahexaenoic acid (DHA, C22:6) [PE (20:3/22:6)]. In addition, breastmilk associated with "faster" growth contained less long-chain triglycerides (TG) containing oleic acid (C18:1) [such as TG (18:1/18:1/18:2), TG (16:0/17:1/18:1) and TG (18:0/18:1/18:1)]. Finally, several eicosanoids, including many DGLA-derived oxylipins [15S-HpEDE, 11-deoxy-16, 16-dimethyland 9-deoxy-9-methylene-16,16-dimethyl-PGE2], and Lyso-phospholipids (PL) [LysoPS (22:0) and LysoPG (22:4)] were lower in the breast milk provided to preterm infants with "faster" growth.

\subsection{Reliability of Maternal Milk Lipids Biomarkers Regarding Postnatal Infant's Growth}

To assess the reliability of putative biomarkers as predictors of preterm infants' growth during hospital stay, we considered the multiple testing filtering (i.e., adjusted FDR $p$-value < 0.05) (Step 3), combined, only for lipidomic LC-HRMS signatures, to the multivariate selection operated by the previously described AoV-PLS/LDA model. This approach led to the selection of four fatty acids [MCSAT and oleic acid (with a $p$-value of 0.051), EPA and DHA] and 46 robust biomarkers of infant postnatal growth, which were annotated and are reported in bold font in Tables 2 and 3, respectively. In addition, the reliability of these selected biomarkers to predict postnatal growth rate was evaluated using a multiple linear regression (MLR) analysis (Step 4) to explain the change in weight Z-score between birth and hospital discharge. Several confounding clinical factors (mother's body mass index, birth weight, gestational age, complementary parenteral and enteral nutrition with the protein, lipid and energy intakes, duration of parenteral feeding and ventilation and length of hospital-stay) were introduced in MLR models. The resulting MLR $p$-values of all these putative biomarkers are listed in Table 4. 
Table 3. Abundance $\left(10^{6}\right)$ of annotated lipids that discriminated lipidotypes of breast milk provided to preterm infants with "faster" or "slower" growth during the W2-W4 lactation period.

\begin{tabular}{|c|c|c|c|c|c|}
\hline \multirow{2}{*}{ Lipids } & \multirow{2}{*}{$\mathbf{m z}$} & \multicolumn{2}{|c|}{ Median [25\% and $75 \%$ Percentile] from W2 to W4 } & \multirow{3}{*}{$\begin{array}{c}\text { Mann-Whitney U } \\
p \text {-Value from W2 } \\
\text { to W4 } \\
0.191\end{array}$} & \multirow{2}{*}{$\begin{array}{l}\text { FDR Corrected } \\
q \text {-Value from W2 } \\
\text { to } \mathbf{W} 4\end{array}$} \\
\hline & & "Slower" Growth $(n=38)$ & "Faster" Growth $(n=29)$ & & \\
\hline Fatty acid & & $9.47(7.40-12.84)$ & $8.39(5.53-13.00)$ & & \\
\hline Anandamide (C18:3. n-6) & $339.2889\left[\mathrm{M}+\mathrm{NH}_{4}\right]^{+}$ & $8.80(7.02-11.77)$ & $7.43(5.11-11.47)$ & 0.119 & 0.133 \\
\hline 3-Hydroxyadipic acid & $161.0455[\mathrm{M}-\mathrm{H}]^{-}$ & $17.17(14.02-20.25)$ & $11.85(5.68-15.09)$ & 0.000 & 0.000 \\
\hline $\mathrm{N}$-formylmaleamic acid & $142.0203[\mathrm{M}-\mathrm{H}]^{-}$ & $1.26(0.84-1.64)$ & $0.73(0.59-0.97)^{c}$ & 0.000 & 0.000 \\
\hline Dodecatetraenedioic acid & $221.0667[\mathrm{M}-\mathrm{H}]^{-}$ & $0.77(0.53-0.88)$ & $0.55(0.34-0.73)^{\mathrm{b}}$ & 0.000 & 0.001 \\
\hline Linderic acid & $187.1340[\mathrm{M}-\mathrm{H}]^{-}$ & $0.52(0.38-1.43)$ & $0.76(0.42-1.80)$ & 0.282 & 0.066 \\
\hline alpha-hydroxy lauric acid & $215.1653[\mathrm{M}-\mathrm{H}]^{-}$ & $4.06(2.39-8.23)$ & $5.08(2.51-13.03)$ & 0.433 & 0.087 \\
\hline 2-hydroxy palmitic acid & $271.2281[\mathrm{M}-\mathrm{H}]^{-}$ & $38.63(22.48-48.63)$ & $37.44(29.98-50.32)$ & 0.769 & 0.126 \\
\hline 3-oxo-4-pentenoic acid & $113.0243[\mathrm{M}-\mathrm{H}]^{-}$ & $1.43(1.18-1.71)$ & $0.94(0.69-1.28)^{c}$ & 0.000 & 0.000 \\
\hline Dehydrocholic acid & $401.2312[\mathrm{M}-\mathrm{H}]^{-}$ & $0.43(0.21-0.73)$ & $0.52(0.33-0.97)$ & 0.211 & 0.054 \\
\hline 7R.9.14R-trimethyl-2E.4E.8E.10E-hexadecatetraenoic acid & $289.2169[\mathrm{M}-\mathrm{H}]^{-}$ & $0.19(0.10-0.48)$ & $0.27(0.14-0.46)$ & 0.326 & 0.072 \\
\hline Ceramide & & $15.56(12.98-18.63)$ & $20.27(17.34-23.79)^{c}$ & 0.000 & 0.000 \\
\hline Cer (18:1/22:0) & $\begin{array}{c}622.6123[\mathrm{M}+\mathrm{H}]^{+} 604.6017[\mathrm{M}+ \\
\left.\mathrm{H}-\mathrm{H}_{2} \mathrm{O}\right]^{+} 644.5491[\mathrm{M}+\mathrm{Na}]^{+}\end{array}$ & $1.03(0.89-1.38)$ & $1.36(1.14-1.69)^{\mathrm{b}}$ & 0.005 & 0.032 \\
\hline Cer (d18:1/24:0) & $\begin{array}{c}632.6326\left[\mathrm{M}-\mathrm{H}_{2} \mathrm{O}\right]^{+} \\
650.643[\mathrm{M}+\mathrm{H}]^{+}\end{array}$ & $14.59(12.11-17.50)$ & $18.78(16.21-22.15)^{\mathrm{c}}$ & 0.000 & 0.011 \\
\hline GlucosylCeramide & & $511.4(487.8-574.5)$ & $519.5(483.9-558.1)$ & 0.764 & 0.385 \\
\hline Glucosylceramide (d18:2/14:0) & $685.5361\left[\mathrm{M}+\mathrm{NH}_{4}\right]^{+}$ & $32.05(13.43-46.52)$ & $26.70(13.73-41.90)$ & 0.519 & 0.343 \\
\hline Galactosylceramide (d18:1/18:1) & $743.614\left[\mathrm{M}+\mathrm{NH}_{4}\right]^{+}$ & $322.7(309.6-355.8)$ & $340.8(316.5-348.9)$ & 0.543 & 0.355 \\
\hline Galactosylceramide (d18:1/20:0) & $773.652\left[\mathrm{M}+\mathrm{NH}_{4}\right]^{+}$ & $31.36(29.58-33.78)$ & $31.52(30.08-33.87)$ & 0.734 & 0.424 \\
\hline Glucosylceramide (d18:1/16:0) & $717.5892\left[\mathrm{M}+\mathrm{NH}_{4}\right]^{+}$ & $42.06(34.50-48.39)$ & $42.43(35.90-48.07)$ & 0.9440 & 0.492 \\
\hline Glucosylceramide (d18:1/18:0) & $728.5481[\mathrm{M}+\mathrm{H}]^{+}$ & $2.28(1.54-2.87)$ & $1.85(1.18-2.24)^{\mathrm{b}}$ & 0.004 & 0.032 \\
\hline Glucosylceramide (d18:1/20:0) & $773.6614\left[\mathrm{M}+\mathrm{NH}_{4}\right]^{+}$ & $20.89(19.20-22.66)$ & $19.24(15.94-22.67)$ & 0.092 & 0.116 \\
\hline Glucosylceramide (d18:1/24:0) & $854.7266[\mathrm{M}+\mathrm{Na}]^{+}$ & $57.94(54.82-62.99)$ & $62.46(56.55-66.47)^{\mathrm{t}}$ & 0.068 & 0.099 \\
\hline Phosphocholine & & $357.0(315.6-456.2)$ & $453.3(370.1-568.0)^{b}$ & 0.006 & 0.009 \\
\hline$P C(18: 0 / 18: 1)$ & $788.5863[\mathrm{M}+\mathrm{H}]^{+}$ & $2.59(1.55-4.34)$ & $4.16(3.06-5.25)^{\mathrm{a}}$ & 0.025 & 0.064 \\
\hline PC (14:0/16:0) & $706.5391[\mathrm{M}+\mathrm{H}]^{+}$ & $1.54(1.09-2.63)$ & $1.830(1.47-3.3)^{\mathrm{t}}$ & 0.134 & 0.142 \\
\hline PC (14:0/16:1) & $704.5237[\mathrm{M}+\mathrm{H}]^{+}$ & $0.20(0.09-0.40)$ & $0.25(0.13-0.50)$ & 0.277 & 0.224 \\
\hline PC (20:0/20:2) & $842.636[\mathrm{M}+\mathrm{H}]^{+}$ & $1.49(1.11-2.33)$ & $2.33(178-3.33)^{b}$ & 0.017 & 0.053 \\
\hline PC (16:1/18:1) & $1620.1146\left[\mathrm{M}+\mathrm{HPO}_{3}+2 \mathrm{H}\right]^{+}$ & $1.06(0.89-1.21)$ & $1.03(0.89-1.14)$ & 0.351 & 0.358 \\
\hline PC (16:1/18:0) & $1542.1426[2 \mathrm{M}+\mathrm{Na}]+$ & $11.76(8.45-13.37)$ & $10.58(9.23-11.88)$ & 0.387 & 0.277 \\
\hline$P C(16: 1 / 18: 2)$ & $1512.1349[2 \mathrm{M}+\mathrm{H}]+$ & $2.33(1.70-2.96)$ & $3.23(1.762-3.79)^{t}$ & 0.030 & 0.069 \\
\hline PC (18:0/18:1) & $1576.2229[2 \mathrm{M}+\mathrm{H}]+$ & $12.09(7.30-23.45)$ & $16.68(8.09-28.81)$ & 0.150 & 0.153 \\
\hline$P C(18: 1 / 18: 1)$ & $1572.1908[2 \mathrm{M}+\mathrm{H}]+$ & $103.2(84.86-131.5)$ & $127.6(99.45-164.00)^{\mathrm{a}}$ & 0.036 & 0.074 \\
\hline PC (18:0/18:2) & $786.5899[\mathrm{M}+\mathrm{H}]^{+}$ & $7.02(5.92-9.61)$ & $10.60(8.13-13.21)^{c}$ & 0.000 & 0.016 \\
\hline PC (16:0/20:3) & $784.5833[\mathrm{M}+\mathrm{H}]^{+}$ & $51.58(41.81-65.60)$ & $65.96(52.12-85.89)^{\mathrm{b}}$ & 0.004 & 0.030 \\
\hline PC (18:0/20:1) & $816.6456[\mathrm{M}+\mathrm{H}]^{+}$ & $11.92(7.23-18.88)$ & $12.22(8.59-20.67)$ & 0.386 & 0.277 \\
\hline PC (18:0/20:3) & $812.6143[\mathrm{M}+\mathrm{H}]^{+}$ & $30.80(25.22-44.50)$ & $46.59(37.16-55.24)^{\mathrm{c}}$ & 0.000 & 0.016 \\
\hline PC (18:0/20:5) & $808.5806[\mathrm{M}+\mathrm{H}]^{+}$ & 93.34 (74.64-112.8) & 94.55 (78.87-119.9) & 0.343 & 0.256 \\
\hline PC (20:1/20:4) & $836.6145[\mathrm{M}+\mathrm{H}]^{+}$ & $3.72(2.96-4.54)$ & $4.88(3.77-6.26)^{\mathrm{a}}$ & 0.007 & 0.037 \\
\hline PC (18:0/22:6) & $834.596[\mathrm{M}+\mathrm{H}]^{+}$ & $11.95(8.65-15.21)$ & $12.61(10.11-17.45)$ & 0.153 & 0.154 \\
\hline
\end{tabular}


Table 3. Cont

\begin{tabular}{|c|c|c|c|c|c|}
\hline \multirow{2}{*}{ Lipids } & \multirow{2}{*}{$\mathbf{m z}$} & \multicolumn{2}{|c|}{ Median [ $25 \%$ and $75 \%$ Percentile] from W2 to W4 } & \multirow{2}{*}{$\begin{array}{c}\text { Mann-Whitney U } \\
p \text {-Value from W2 } \\
\text { to W4 }\end{array}$} & \multirow{2}{*}{$\begin{array}{c}\text { FDR Corrected } \\
q \text {-Value from W2 } \\
\text { to } \mathrm{W} 4\end{array}$} \\
\hline & & "Slower" Growth $(n=38)$ & "Faster" Growth $(n=29)$ & & \\
\hline PC (20:3/22:6) & $856.5807[\mathrm{M}+\mathrm{H}]^{+}$ & $5.42(3.95-6.97)$ & $6.46(5.06-7.62)^{\mathrm{a}}$ & 0.013 & 0.047 \\
\hline PC (16:0/22:6) & $806.5678[\mathrm{M}+\mathrm{H}]^{+}$ & $12.08(7.25-16.08)$ & $16.07(12.04-24.40)^{\mathrm{a}}$ & 0.007 & 0.037 \\
\hline PC-plasmalogen & & $8.16(6.53-10.52)$ & $8.88(6.97-12.23)$ & 0.273 & 0.236 \\
\hline PC (P-18:0/18:0) & $796.6199[\mathrm{M}+\mathrm{Na}]^{+}$ & $1.72(1.19-2.49)$ & $2.32(1.85-3.09)^{\mathrm{b}}$ & 0.008 & 0.037 \\
\hline PC (P-16:0/18:2) & $742.5723[\mathrm{M}+\mathrm{H}]^{+}$ & $2.18(1.61-2.98)$ & $1.59(1.09-2.52]^{\mathrm{t}}$ & 0.104 & 0.124 \\
\hline PC (O-16:0/18:1) & $768.5514[\mathrm{M}+\mathrm{H}]+$ & $4.11(3.36-5.58)$ & $4.82(3.42-6.81)$ & 0.114 & 0.131 \\
\hline Phosphoethanolamine & & 279.4(253.2-317.5) & $316.5(283.1-356.3)^{b}$ & 0.002 & 0.004 \\
\hline PE (16:0/16:1) & $690.5054[\mathrm{M}+\mathrm{H}]^{+}$ & $1.79(1.59-2.22)$ & $2.15(1.93-2.45)^{\mathrm{b}}$ & 0.005 & 0.032 \\
\hline$P E(16: 1 / 20: 0)$ & $1492.1294[2 \mathrm{M}+\mathrm{H}]++$ & $6.72(5.45-8.88)$ & $8.38(6.85-10.43)^{\mathrm{a}}$ & 0.037 & 0.074 \\
\hline$P E(16: 0 / 20: 2)$ & $1488.0975[2 \mathrm{M}+\mathrm{H}]+$ & $21.16(18.3-27.46)$ & $27.62(18.61-34.14)^{\mathrm{a}}$ & 0.039 & 0.075 \\
\hline PE (16:0/20:2) & $744.5519[\mathrm{M}+\mathrm{H}]^{+}$ & $142.2(132.7-168.4)$ & $166.6(151.1-179.3)^{\mathrm{a}}$ & 0.016 & 0.050 \\
\hline $\operatorname{PE}(16: 0 / 20: 4)$ & $779.5379[\mathrm{M}+\mathrm{Na}]^{+}$ & $0.67(0.57-0.87)$ & $0.81(0.61-1.19)^{\mathrm{a}}$ & 0.044 & 0.079 \\
\hline $\operatorname{PE}(18: 0 / 20: 0)$ & $776.60[\mathrm{M}+\mathrm{H}]^{+}$ & $1.68(1.29-2.50)$ & $1.52(1.25-1.73)^{\mathrm{t}}$ & 0.131 & 0.141 \\
\hline PE (20:1/20:4) & $794.5676[\mathrm{M}+\mathrm{H}]^{+}$ & $7.45(6.07-10.05)$ & $9.41(8.22-10.29)^{\mathrm{a}}$ & 0.030 & 0.069 \\
\hline PE (18:0/20:4) & $1536.0968[2 \mathrm{M}+\mathrm{H}]++$ & $4.93(3.62-7.23)$ & $7.71(5.28-9.57)^{\mathrm{b}}$ & 0.004 & 0.030 \\
\hline PE (22:0/20:3) & $826.6047[\mathrm{M}+\mathrm{H}]^{+}$ & $2.09(1.53-2.61)$ & $2.51(2.18-3.48)^{\mathrm{b}}$ & 0.006 & 0.033 \\
\hline PE (18:1/18:2) & $1484.067[2 \mathrm{M}+\mathrm{H}]+$ & $2.79(1.97-3.99)$ & $3.14(2.07-4.36)$ & 0.665 & 0.398 \\
\hline PE (16:0/20:4) & $740.5208[\mathrm{M}+\mathrm{H}]^{+}$ & $7.75(5.31-9.68)$ & $7.18(5.44-9.98)$ & 0.468 & 0.321 \\
\hline PE (18:2/18:2) & $740.5213[\mathrm{M}+\mathrm{H}]^{+}$ & $4.76(3.58-5.70)$ & $6.21(4.92-7.41)^{\mathrm{b}}$ & 0.006 & 0.035 \\
\hline PE (20:0/18:1) & $774.599[\mathrm{M}+\mathrm{H}]^{+}$ & $6.92(5.61-9.12)$ & $9.24(7.24-11.69)^{\mathrm{b}}$ & 0.004 & 0.030 \\
\hline PE (18:0/20:4) & $768.5495[\mathrm{M}+\mathrm{H}]^{+}$ & $13.52(12.42-14.25)$ & $14.14(13.13-15.75)^{\mathrm{t}}$ & 0.094 & 0.118 \\
\hline PE (20:4/20:0) & $796.5836[\mathrm{M}+\mathrm{H}]^{+}$ & $6.13(4.98-8.72)$ & $8.63(6.81-10.52)^{\mathrm{b}}$ & 0.007 & 0.035 \\
\hline PE (22:6/18:0) & $792.5517[\mathrm{M}+\mathrm{H}]^{+}$ & $17.55(12.31-22.26)$ & $20.02(15.51-25.01)$ & 0.085 & 0.112 \\
\hline PE (20:3/22:6) & $814.5336[\mathrm{M}+\mathrm{H}]^{+}$ & $2.63(1.96-3.06)$ & $3.14(2.58-3.59)^{\mathrm{c}}$ & 0.002 & 0.023 \\
\hline $\operatorname{PE}(22: 0 / 22: 6)$ & $848.6566[\mathrm{M}+\mathrm{H}]^{+}$ & $4.69(3.55-6.02)$ & $4.25(2.64-4.98)$ & 0.131 & 0.141 \\
\hline PE (18:0/20:3) & $770.5672[\mathrm{M}+\mathrm{H}]^{+}$ & $12.72(10.13-16.13)$ & $17.21(14.84-20.82)^{\mathrm{c}}$ & 0.000 & 0.001 \\
\hline PE-plasmalogen & & $39.91(31.47-49.92)$ & $38.83(34.83-52.40)$ & 0.592 & 0.385 \\
\hline PE (P-16:0/20:5) & $722.5102[\mathrm{M}+\mathrm{H}]^{+}$ & $4.73(3.96-7.45)$ & $5.92(4.46-7.69)$ & 0.119 & 0.133 \\
\hline PE (P-16:0/18:0) & $726.5323[\mathrm{M}+\mathrm{N}]^{+}$ & $10.82(7.93-14.26)$ & $9.44(5.92-13.33)$ & 0.186 & 0.173 \\
\hline PE (P-16:0/20:0) & $754.5636[\mathrm{M}+\mathrm{Na}]^{+}$ & $4.11(2.58-5.23)$ & $3.94(2.25-4.96)$ & 0.343 & 0.256 \\
\hline PE (P-16:0/20:3) & $726.5417[\mathrm{M}+\mathrm{H}]^{+}$ & $10.49(8.45-12.70)$ & $11.39(9.41-14.01)$ & 0.117 & 0.132 \\
\hline PE (O-18:0/20:5) & $752.5551[\mathrm{M}+\mathrm{H}]^{+}$ & $7.84(6.04-9.98)$ & $9.95(7.30-12.09)^{\mathrm{a}}$ & 0.019 & 0.056 \\
\hline Phosphatidylglycerol & & $16.41(15.59-18.36)$ & $18.85(16.90-22.25)^{b}$ & 0.002 & 0.004 \\
\hline PG (16:0/16:0) & $723.5101[\mathrm{M}+\mathrm{H}]^{+}$ & $3.31(2.77-3.90)$ & $3.57(2.85-3.79)$ & 0.475 & 0.324 \\
\hline PG (18:0/20:4) & $799.5425[\mathrm{M}+\mathrm{H}]^{+}$ & $2.11(1.72-2.36)$ & $1.90(1.48-2.25)$ & 0.202 & 0.181 \\
\hline$P G(P-16: 0 / 22: 4)$ & $783.5586[\mathrm{M}+\mathrm{H}]^{+}$ & $1.58(1.26-1.76)$ & $1.93(1.47-2.26)^{\mathrm{a}}$ & 0.021 & 0.058 \\
\hline PG (18:2/20:5) & $810.523\left[\mathrm{M}+\mathrm{NH}_{4}\right]^{+}$ & $6.52(5.64-7.40)$ & $7.67(6.61-9.94)^{\mathrm{b}}$ & 0.001 & 0.016 \\
\hline$P G(22: 2 / 22: 6)$ & $892.5991\left[\mathrm{M}+\mathrm{NH}_{4}\right]^{+}$ & $3.20(2.97-3.61)$ & $3.56(3.12-3.91)^{\mathrm{a}}$ & 0.035 & 0.074 \\
\hline \multicolumn{6}{|l|}{ Phosphinositol } \\
\hline PI (36:0) PI (18:0/18:0) & $889.5716[\mathrm{M}+\mathrm{Na}]^{+}$ & $0.92(0.78-1.39)$ & $1.26(0.89-2.20)^{\mathrm{a}}$ & 0.055 & 0.087 \\
\hline \multicolumn{6}{|l|}{ Phosphoserine } \\
\hline PS (40:5) & $838.552[\mathrm{M}+\mathrm{H}]^{+}$ & $2.72(2.52-3.06)$ & $2.95(2.64-3.11)$ & 0.186 & 0.173 \\
\hline PS (18:0/20:4) & $812.5419[\mathrm{M}+\mathrm{H}]^{+}$ & $2.13(1.59-2.77)$ & $2.79(2.29-3.26)^{b}$ & 0.002 & 0.023 \\
\hline
\end{tabular}


Table 3. Cont

\begin{tabular}{|c|c|c|c|c|c|}
\hline \multirow{2}{*}{ Lipids } & \multirow{2}{*}{$\mathrm{mz}$} & \multicolumn{2}{|c|}{ Median [ $25 \%$ and $75 \%$ Percentile] from W2 to W4 } & \multirow{2}{*}{$\begin{array}{l}\text { Mann-Whitney U } \\
p \text {-Value from W2 }\end{array}$} & \multirow{2}{*}{$\begin{array}{l}\text { FDR Corrected } \\
q \text {-Value from W2 }\end{array}$} \\
\hline & & "Slower" Growth $(n=38)$ & "Faster" Growth $(n=29)$ & & \\
\hline Retinol & $287.2362[\mathrm{M}+\mathrm{H}]^{+}$ & $2.02(1.33-2.97)$ & $1.57(1.10-3.11)$ & $\begin{array}{l}\operatorname{tn} W 4 \\
0.752\end{array}$ & $\begin{array}{l}+5 W \mathrm{~A} \\
0.429\end{array}$ \\
\hline Diacylglyceride & & $104.0(66.98-163.6)$ & $92.39(52.86-126.5)$ & 0.183 & 0.192 \\
\hline$D G(14: 0 / 18: 3)$ & $580.5373[\mathrm{M}+\mathrm{Na}]^{+}$ & $8.52(3.30-15.47)$ & $4.92(2.30-9.16)^{\mathrm{a}}$ & 0.025 & 0.064 \\
\hline DG (16:0/16:1) & $567.4974[\mathrm{M}+\mathrm{H}]^{+}$ & $6.61(3.88-7.99)$ & $5.26(3.05-11.07)$ & 0.656 & 0.395 \\
\hline DG 18:0/18:1) & $645.544[\mathrm{M}+\mathrm{Na}]^{+}$ & $7.56(5.03-7.58)$ & $6.90(5.51-11.53)$ & 0.797 & 0.444 \\
\hline$D G(18: 0 / 18: 2)$ & $638.5708\left[\mathrm{M}+\mathrm{NH}_{4}\right]^{+}$ & $55.02(36.04-87.52)$ & $40.60(22.83-66.09)^{\mathrm{t}}$ & 0.045 & 0.079 \\
\hline DG (18:0/18:1) & $634.5395\left[\mathrm{M}+\mathrm{NH}_{4}\right]^{+}$ & $10.80(5.53-17.81)$ & $10.46(7.75-17.81)$ & 0.582 & 0.370 \\
\hline DG (20:4/19:0) & $681.5402[\mathrm{M}+\mathrm{Na}]^{+}$ & $0.92(0.47-1.60)$ & $1.07(0.60-2.03)$ & 0.292 & 0.233 \\
\hline DG $(20: 3: / 20: 0)$ & $697.5727[\mathrm{M}+\mathrm{Na}]^{+}$ & $4.98(2.91-9.25)$ & $2.74(1.64-4.81)^{\mathrm{a}}$ & 0.027 & 0.065 \\
\hline DG $(18: 3 / 20: 0)$ & $647.5574[\mathrm{M}+\mathrm{H}]^{+}$ & $6.81(2.59-13.46)$ & $4.06(1.51-9.17)^{\mathrm{t}}$ & 0.079 & 0.107 \\
\hline$D G(20: 4 / 22: 5)$ & $713.5103[\mathrm{M}+\mathrm{Na}]^{+}$ & $0.56(0.24-0.79)$ & $0.26(0.15-0.56)^{\mathrm{a}}$ & 0.040 & 0.076 \\
\hline Triglyceride & & 7758 (7304-8118) & 7572 (7236-8496) & 0.717 & 0.385 \\
\hline TG (14:0/16:1/17:2) & $804.7056\left[\mathrm{M}+\mathrm{NH}_{4}\right]^{+}$ & $55.94(47.00-60.12)$ & $59.35(52.54-69.66)^{\mathrm{a}}$ & 0.011 & 0.043 \\
\hline TG (14:0/14:1/14:1) & $741.5983[\mathrm{M}+\mathrm{Na}]^{+}$ & $415.0(358.3-520.8)$ & $415.2(371.5-448.9)$ & 0.972 & 0.499 \\
\hline TG (14:0/16:0/16:0) & $796.7277\left[\mathrm{M}+\mathrm{NH}_{4}\right]^{+}$ & $337.3(308.2-373.3)$ & $381.5(340.2-439.9)^{\mathrm{b}}$ & 0.003 & 0.030 \\
\hline TG (14:1/14:1/18:1) & $790.6895\left[\mathrm{M}+\mathrm{NH}_{4}\right]^{+}$ & $1074(923.6-1296)$ & 1074 (911.2-1330) & 0.788 & 0.442 \\
\hline TG (14:0/14:1/19:1) & $806.712\left[\mathrm{M}+\mathrm{NH}_{4}\right]^{+}$ & $9.17(7.68-10.01)$ & $9.81(8.58-10.81)^{\mathrm{a}}$ & 0.012 & 0.046 \\
\hline TG (13:0/14:1/20:5) & $798.6639\left[\mathrm{M}+\mathrm{NH}_{4}\right]^{+}$ & $117.1(114.0-124.0)$ & $118.9(111.6-124.5)$ & 0.743 & 0.427 \\
\hline$T G(16: 0 / 16: 1 / 16: 1)$ & $820.7365\left[\mathrm{M}+\mathrm{NH}_{4}\right]^{+}$ & $2033(1831-2139)$ & $2142(1937-2447)^{a}$ & 0.028 & 0.067 \\
\hline TG (14:0/16:0/16:0) & $801.6948[\mathrm{M}+\mathrm{Na}]^{+}$ & $25.93(21.63-28.64)$ & $29.18(24.40-36.14)^{\mathrm{b}}$ & 0.019 & 0.057 \\
\hline TG (16:1/16:1/16:1) & $823.676[\mathrm{M}+\mathrm{Na}]^{+}$ & $257.9(246.2-272.9)$ & $258.8(244.0-270.8)$ & 0.639 & 0.388 \\
\hline TG $(16: 1 / 16: 1 / 17: 1)$ & $832.7368\left[\mathrm{M}+\mathrm{NH}_{4}\right]^{+}$ & $74.98(64.31-82.97)$ & 76.59 (69.19-90.90) & 0.178 & 0.169 \\
\hline TG (14:0/15:0/20:5) & $828.7134\left[\mathrm{M}+\mathrm{NH}_{4}\right]^{+}$ & $10.48(8.74-11.70)$ & $11.27(9.79-12.47)$ & 0.178 & 0.169 \\
\hline TG $(16: 0 / 16: 1 / 18: 0)$ & $850.7742\left[\mathrm{M}+\mathrm{NH}_{4}\right]^{+}$ & $320.2(306.7-334.3)$ & 325.7 (308.6-364.5) & 0.099 & 0.121 \\
\hline$T G(16: 0 / 17: 1 / 18: 1)$ & $862.8205\left[\mathrm{M}+\mathrm{NH}_{4}\right]^{+}$ & $3.37(2.70-5.18)$ & $2.93(2.00-3.59)^{\mathrm{t}}$ & 0.051 & 0.083 \\
\hline$T G(16: 0 / 16: 0 / 18: 1)$ & $850.7655\left[\mathrm{M}+\mathrm{NH}_{4}\right]^{+}$ & $12.01(10.70-13.14)$ & $11.06(9.80-12.04)^{1}$ & 0.021 & 0.058 \\
\hline TG (16:1/16:1/17:2) & $830.7291\left[\mathrm{M}+\mathrm{NH}_{4}\right]^{+}$ & $10.40(9.81-10.85)$ & $10.65(9.44-11.54)$ & 0.606 & 0.378 \\
\hline TG $(18: 1 / 20: 1 / 22: 1)$ & $986.9093\left[\mathrm{M}+\mathrm{NH}_{4}\right]^{+}$ & $3.29(2.50-4.13)$ & $2.51(1.83-4.16]$ & 0.111 & 0.128 \\
\hline TG (16:1/16:1/18:2) & $844.7364\left[\mathrm{M}+\mathrm{NH}_{4}\right]^{+}$ & $147.3(130.4-182.8)$ & $182.8(156.9-240.3)^{\mathrm{b}}$ & 0.002 & 0.022 \\
\hline TG (16:1/16:1/17:2) & $835.6764[\mathrm{M}+\mathrm{Na}]^{+}$ & $3.64(3.20-4.61)$ & $3.53(3.09-3.89)$ & 0.178 & 0.169 \\
\hline$T G(16: 0 / 16: 0 / 16: 1)$ & $827.7101[\mathrm{M}+\mathrm{Na}]^{+}$ & $19.01(15.59-21.21)$ & $21.55(17.11-25.06)^{\mathrm{t}}$ & 0.036 & 0.074 \\
\hline TG (16:1/18:4/18:4) & $862.6902\left[\mathrm{M}+\mathrm{NH}_{4}\right]^{+}$ & $4.35(2.97-6.41)$ & $6.37(3848-9.41)^{a}$ & 0.014 & 0.047 \\
\hline TG $(16: 0 / 17: 2 / 18: 1)$ & $860.7679\left[\mathrm{M}+\mathrm{NH}_{4}\right]^{+}$ & $184.9(156.0-222.3)$ & $190.3(171.0-220.9)$ & 0.320 & 0.247 \\
\hline TG (16:0/16:0/17:2) & $839.7451[\mathrm{M}+\mathrm{Na}]^{+}$ & $1.57(1.37-1.71)$ & $1.47(1.32-1.64)$ & 0.114 & 0.131 \\
\hline TG $(18: 1 / 18: 3 / 20: 0)$ & $935.7928[\mathrm{M}+\mathrm{Na}]^{+}$ & $3.76(3.35-4.49)$ & $4.00(3.24-4.74)$ & 0.639 & 0.388 \\
\hline TG (18:0/18:1/20:3) & $933.7851[\mathrm{M}+\mathrm{Na}]^{+}$ & $19.46(17.47-22.81)$ & $18.90(17.36-23.78)$ & 0.963 & 0.497 \\
\hline$T G(18: 2 / 18: 2 / 20: 0)$ & $930.8363\left[\mathrm{M}+\mathrm{NH}_{4}\right]^{+}$ & $21.21(18.33-23.40)$ & $17.47(15.95-23.86)^{\mathrm{t}}$ & 0.055 & 0.088 \\
\hline TG (18:0/18:1/18:1) & $904.83\left[\mathrm{M}+\mathrm{NH}_{4}\right]^{+}$ & $387.1(333.1-451.4)$ & $341.6(267.7-385.0)^{\mathrm{a}}$ & 0.015 & 0.049 \\
\hline TG (18:0/18:1/18:1) & $906.8364\left[\mathrm{M}+\mathrm{NH}_{4}\right]^{+}$ & $81.24(74.07-95.84)$ & $75.22(56.50-84.79)^{\mathrm{a}}$ & 0.025 & 0.064 \\
\hline TG (18:1/18:1/18:1) & $902.8144\left[\mathrm{M}+\mathrm{NH}_{4}\right]^{+}$ & $956.4(818.7-1069)$ & $878.3(810.2-1074)$ & 0.242 & 0.203 \\
\hline TG (16:0/18:0/18:1) & $883.761[\mathrm{M}+\mathrm{Na}]^{+}$ & $41.08(33.90-44.66)$ & 42.83 (40.77-45.25) & 0.233 & 0.198 \\
\hline TG (18:1/18:1/18:2) & $900.7896\left[\mathrm{M}+\mathrm{NH}_{4}\right]^{+}$ & $246.9(224.0-277.0)$ & $225.1(190.1-236.1)^{\mathrm{a}}$ & 0.005 & 0.032 \\
\hline$T G(18: 1 / 18: 2 / 18: 2)$ & $898.7739\left[\mathrm{M}+\mathrm{NH}_{4}\right]^{+}$ & $120.3(75.92-128.3)$ & $96.31(70.34-119.4)^{t}$ & 0.034 & 0.073 \\
\hline TG (18:0/18:1/18:2) & $902.8052\left[\mathrm{M}+\mathrm{NH}_{4}\right]^{+}$ & $260.5(233.8-281.8)$ & $243.6(211.4-295.7)$ & 0.246 & 0.205 \\
\hline
\end{tabular}


Table 3. Cont.

\begin{tabular}{|c|c|c|c|c|c|}
\hline \multirow{2}{*}{ Lipids } & \multirow{2}{*}{$\mathrm{mz}$} & \multicolumn{2}{|c|}{ Median [25\% and $75 \%$ Percentile] from W2 to W4 } & \multirow{2}{*}{$\begin{array}{l}\text { Mann-Whitney U } \\
p \text {-Value from W2 } \\
\text { to W4 }\end{array}$} & \multirow{2}{*}{$\begin{array}{l}\text { FDR Corrected } \\
q \text {-Value from } \mathrm{W} \\
\text { to } \mathrm{W}_{4}\end{array}$} \\
\hline & & "Slower" Growth $(n=38)$ & "Faster" Growth $(n=29)$ & & \\
\hline TG (16:0/17:1/20:5) & $882.7478\left[\mathrm{M}+\mathrm{NH}_{4}\right]^{+}$ & $8.63(8.18-9.64)$ & $8.31(7.60-8.83)^{\mathrm{a}}$ & 0.001 & 0.016 \\
\hline TG (18:1/20:1/22:3) & $982.8773\left[\mathrm{M}+\mathrm{NH}_{4}\right]^{+}$ & $2.52(1.96-3.30)$ & $1.94(1.43-3.51)$ & 0.119 & 0.133 \\
\hline$T G(18: 1 / 18: 2 / 20: 0)$ & $930.8455\left[\mathrm{M}+\mathrm{NH}_{4}\right]^{+}$ & 78.44 (71.25-95.93) & $71.54(58.23-93.06)^{\mathrm{t}}$ & 0.059 & 0.091 \\
\hline $\mathrm{TG}(18: 2 / 20: 4 / 20: 4)$ & $944.7669\left[\mathrm{M}+\mathrm{NH}_{4}\right]^{+}$ & $39.93(29.65-52.66)$ & $29.27(22.13-49.46)$ & 0.094 & 0.118 \\
\hline TG(18:1/20:4/20:4) & $946.7742\left[\mathrm{M}+\mathrm{NH}_{4}\right]^{+}$ & $8.65(6.97-10.87)$ & $6.77(5.28-11.25)$ & 0.101 & 0.124 \\
\hline TG $(20: 0 / 20: 0 / 20: 4)$ & $989.8484[\mathrm{M}+\mathrm{Na}]^{+}$ & $2.27(1.65-2.85)$ & $1.68(1.41-2.63)$ & 0.106 & 0.125 \\
\hline TG $(18: 2 / 20: 1 / 20: 1)$ & $956.8607\left[\mathrm{M}+\mathrm{NH}_{4}\right]^{+}$ & $18.75(14.96-25.95)$ & $13.52(11.70-23.93)$ & 0.071 & 0.102 \\
\hline TG (18:1/20:2/20:4) & $950.814\left[\mathrm{M}+\mathrm{NH}_{4}\right]^{+}$ & 88.26 (75.04-95.26) & $74.00(62.15-90.20)^{\mathrm{a}}$ & 0.022 & 0.059 \\
\hline TG (18:0/20:3/20:5) & $953.7908[\mathrm{M}+\mathrm{Na}]^{+}$ & $1.89(1.72-2.32)$ & $1.87(1.77-2.48)$ & 0.897 & 0.477 \\
\hline TG $(18: 2 / 20: 1 / 20: 4)$ & $955.8051[\mathrm{M}+\mathrm{Na}]^{+}$ & $2.89(2.46-4.61)$ & $3.50(2.50-4.72)$ & 0.331 & 0.250 \\
\hline TG (16:0/18:0/18:0) & $880.8213\left[\mathrm{M}+\mathrm{NH}_{4}\right]^{+}$ & $119.5(108.1-154.4)$ & $110.0(82.96-128.8)^{\mathrm{t}}$ & 0.077 & 0.107 \\
\hline TG $(18: 1 / 20: 0 / 20: 0)$ & $967.8653[\mathrm{M}+\mathrm{Na}]^{+}$ & $1.69(1.34-2.62)$ & $1.98(1.67-3.13)$ & 0.331 & 0.250 \\
\hline TG $(20: 1 / 20: 1 / 20: 4)$ & $980.8615\left[\mathrm{M}+\mathrm{NH}_{4}\right]^{+}$ & $3.64(2.69-4.41)$ & $2.63(2.16-4.60)$ & 0.119 & 0.133 \\
\hline TG $(18: 0 / 20: 1 / 20: 4)$ & $959.801\left[\mathrm{M}+\mathrm{NH}_{4}\right]^{+}$ & $9.16(8.57-10.72)$ & $8.57(7.13-11.61)$ & 0.298 & 0.235 \\
\hline TG (18:0/20:3/22:0) & $991.8645\left[\mathrm{M}+\mathrm{NH}_{4}\right]^{+}$ & $2.61(1.95-3.24)$ & $1.96(1.69-3.57)$ & 0.153 & 0.154 \\
\hline TG $(20: 2 / 20: 4 / 20: 4)$ & $977.7533\left[\mathrm{M}+\mathrm{NH}_{4}\right]^{+}$ & $3.58(2.55-4.31)$ & $2.76(2.17-4.20)$ & 0.137 & 0.144 \\
\hline Sphingomyéline & & $178.6(122.6-220.0)$ & $188.4(157.9-245.9]$ & 0.480 & 0.363 \\
\hline SM (d18:0/12:0) & $651.5340[\mathrm{M}+\mathrm{H}]^{+}$(isotopic peak) & $0.88(0.52-1.02)$ & $1.04(0.68-1.54)^{\mathrm{a}}$ & 0.011 & 0.044 \\
\hline SM (d18:1/12:0) & $647.5119[\mathrm{M}+\mathrm{H}]^{+}$ & $3.80(2.89-5.56)$ & $5.24(3.99-7.00)^{\mathrm{b}}$ & 0.003 & 0.029 \\
\hline$S M(18: 1 / 14: 0)$ & $675.5425[\mathrm{M}+\mathrm{H}]^{+}$ & $72.48(45.46-98.60)$ & $86.28(68.91-111.24)^{\mathrm{a}}$ & 0.036 & 0.074 \\
\hline $\mathrm{SM}(\mathrm{d} 18: 1 / 16: 0)$ & $725.5552[\mathrm{M}+\mathrm{Na}]^{+}$ & $41.85(31.37-52.33)$ & $39.63(32.05-50.87)$ & 0.907 & 0.481 \\
\hline $\mathrm{SM}(\mathrm{d} 18: 1 / 16: 1)$ & $701.5583[\mathrm{M}+\mathrm{H}]^{+}$ & $13.98(10.63-20.40)$ & $15.97(12.92-17.79)$ & 0.574 & 0.367 \\
\hline $\mathrm{SM}(\mathrm{d} 16: 1 / 18: 1)$ & $723.5399[\mathrm{M}+\mathrm{Na}]^{+}$ & $2.76(2.15-4.12)$ & $2.96(2.47-3.65)$ & 0.682 & 0.405 \\
\hline$S M(18: 1 / 20: 1)$ & $779.6015[\mathrm{M}+\mathrm{Na}]^{+}$ & $3.82(3.20-4.93)$ & $3.29(2.50-4.30)^{\mathrm{b}}$ & 0.026 & 0.065 \\
\hline SM (d18:1/20:2) & $755.5768[\mathrm{M}+\mathrm{H}]^{+}$ & $1.49(1.19-2.17)$ & $1.15(1.01-1.44)^{\mathrm{a}}$ & 0.010 & 0.042 \\
\hline SM $(18: 1 / 20: 1)$ & $757.6205[\mathrm{M}+\mathrm{H}]^{+}$ & $13.82(11.32-18.54)$ & $14.51(12.06-19.27)$ & 1.000 & 0.506 \\
\hline$S M(d 18: 1 / 23: 0)$ & $801.6827[\mathrm{M}+\mathrm{H}]^{+}$ & $5.97(3.64-7.23)$ & $7.21(5.42-9.30)^{\mathrm{a}}$ & 0.048 & 0.081 \\
\hline $\mathrm{SM}(\mathrm{d} 18: 1 / 24: 0)$ & $815.6983[\mathrm{M}+\mathrm{H}]^{+}$ & $7.59(5.81-10.37)$ & $7.50(5.59-9.53)$ & 0.433 & 0.302 \\
\hline \multicolumn{6}{|l|}{ Eicosanoid } \\
\hline 10.11-dihydro-20-trihydroxy-leukotriene B4 & $385.2364[\mathrm{M}-\mathrm{H}]^{-}$ & $9.88(6.00-12.19)$ & $5.66(4.12-7.09)^{\mathrm{c}}$ & 0.000 & 0.000 \\
\hline 20-Trihydroxy-leukotriene-B4 & $383.2208[\mathrm{M}-\mathrm{H}]^{-}$ & $11.22(4.99-24.61)$ & $9.62(7.27-15.02)$ & 0.566 & 0.104 \\
\hline HETE & $319.2278[\mathrm{M}-\mathrm{H}]^{-}$ & $2.32(1.04-0.90)$ & $2.31(1.31-4.47)$ & 0.607 & 0.109 \\
\hline Leukotriene B4 & $335.2227[\mathrm{M}-\mathrm{H}]^{-}$ & $0.51(0.28-0.94)$ & $0.32(0.22-0.60)$ & 0.277 & 0.065 \\
\hline 7.8-ероху-17S-HDHA & $357.2051[\mathrm{M}-\mathrm{H}]^{-}$ & $1.78(0.80-3.71)$ & $1.60(0.90-2.47)$ & 0.691 & 0.119 \\
\hline 15S-HpEDE & $339.2537[\mathrm{M}-\mathrm{H}]^{-}$ & $1.68(1.29-2.45)$ & $1.50(1.27-2.00)$ & 0.292 & 0.068 \\
\hline 11-deoxy-16.16-dimethyl-PGE2 & $363.252[\mathrm{M}-\mathrm{H}]^{-}$ & $52.64(32.17-70.29)$ & $40.19(25.54-50.40)^{\mathrm{a}}$ & 0.014 & 0.007 \\
\hline 9-deoxy-9-methylene-16.16-dimethyl-PGE2 & $377.2676[\mathrm{M}-\mathrm{H}]^{-}$ & $1.38(0.92-3.30)$ & $0.99(0.72-1.56)$ & 0.099 & 0.031 \\
\hline PGF2alpha & $353.2314[\mathrm{M}-\mathrm{H}]^{-}$ & $4.89(3.26-7.50)$ & $4.12(2.76-6.73)$ & 0.150 & 0.042 \\
\hline 11-dehydro-2.3-dinor-TXB2 & $339.2001[\mathrm{M}-\mathrm{H}]^{-}$ & $2.98(1.54-4.17)$ & $3.29(2.23-4.75)$ & 0.147 & 0.041 \\
\hline Lyso-PC/PE & & $31.55(25.78-38.13)$ & $29.07(20.34-40.91)$ & 0.658 & 0.385 \\
\hline LysoPC (16:0) & $454.2921[\mathrm{M}+\mathrm{H}]^{+}$ & $3.76(2.85-4.60)$ & $3.21(2.42-4.48)$ & 0.099 & 0.121 \\
\hline LysoPC (14:0) & $468.3079[\mathrm{M}+\mathrm{H}]^{+}$ & $4.40(3.16-6.06)$ & $5.39(3.52-9.12)$ & 0.131 & 0.141 \\
\hline LysoPE (16:1) & $452.3133[\mathrm{M}+\mathrm{H}]^{+}$ & $1.37(1.03-1.66)$ & $1.65(1.25-2.02)^{a}$ & 0.056 & 0.088 \\
\hline
\end{tabular}


Table 3. Cont.

\begin{tabular}{|c|c|c|c|c|c|}
\hline \multirow{2}{*}{ Lipids } & \multirow{2}{*}{$\mathrm{mz}$} & \multicolumn{2}{|c|}{ Median [25\% and $75 \%$ Percentile] from $\mathrm{W} 2$ to $\mathrm{W} 4$} & \multirow{2}{*}{$\begin{array}{c}\text { Mann-Whitney U } \\
p \text {-Value from W2 } \\
\text { to W4 }\end{array}$} & \multirow{2}{*}{$\begin{array}{c}\text { FDR Corrected } \\
q \text {-Value from W2 } \\
\text { to W4 }\end{array}$} \\
\hline & & "Slower" Growth $(n=38)$ & "Faster" Growth $(n=29)$ & & \\
\hline LysoPE (18:1) & $480.3079[\mathrm{M}+\mathrm{H}]^{+}$ & $11.25(7.84-16.01)$ & $8.82(6.71-12.77)$ & 0.079 & 0.107 \\
\hline LysoPE (20:5) & $500.274[\mathrm{M}+\mathrm{H}]^{+}$ & $3.34(2.75-4.56)$ & $2.94(2.13-5.07)$ & 0.198 & 0.179 \\
\hline LysoPE (20:3) & $504.3058[\mathrm{M}+\mathrm{H}]^{+}$ & $2.96(2.23-3.56)$ & $3.09(2.42-4.50)$ & 0.122 & 0.058 \\
\hline LysoPE (20:4) & $502.2902[\mathrm{M}+\mathrm{H}]^{+}$ & $3.58(2.49-4.38)$ & $2.43(1.74-3.27)^{\mathrm{a}}$ & 0.020 & 0.043 \\
\hline LysoPS (22:0) & $580.3535[\mathrm{M}-\mathrm{H}]^{-}$ & $0.51(0.32-1.07)$ & $0.43(0.18-0.86)$ & 0.157 & 0.001 \\
\hline LysoPG (22:4) & $559.2853[\mathrm{M}-\mathrm{H}]^{-}$ & $0.70(0.49-0.89)$ & $0.30(0.20-0.68)^{\mathrm{c}}$ & 0.000 & 0.019 \\
\hline LysoPA (20:0) & $465.3048[\mathrm{M}-\mathrm{H}]^{-}$ & $4.19(3.39-4.93)$ & $5.75(3.75-8.59)^{\mathrm{a}}$ & 0.052 & 0.038 \\
\hline \multicolumn{6}{|l|}{ Cardiolipine } \\
\hline$C L(18: 1 / 18: 1 / 20: 4 / 18: 0)$ & $739.5129[\mathrm{M}-2 \mathrm{H}]^{-}$ & $2.40(1.32-3.57)$ & $2.74(2.04-3.22)$ & 0.419 & 0.086 \\
\hline CL $(18: 2 / 20: 0 / 20: 0 / 20: 4)$ & $767.5439[\mathrm{M}-2 \mathrm{H}]^{-}$ & $3.21(1.45-4.41)$ & $2.87(1.68-4.54)$ & 0.842 & 0.134 \\
\hline
\end{tabular}


Table 4. Predictive ability of tentative lipid and fatty acid biomarkers on infant' growth (defined based on the difference between discharge and birth weight Z-score).

\begin{tabular}{|c|c|}
\hline & $\begin{array}{l}\text { Infant' Weight Growth between Birth and } \\
\text { Discharge (SD) ( } p \text {-Value Corrected-MLR) }\end{array}$ \\
\hline \multicolumn{2}{|l|}{ Fatty Acids (Targeted Analysis) } \\
\hline 12:00 & 0.0043 \\
\hline 14:00 & 0.0005 \\
\hline SAT & 0.2429 \\
\hline MCSAT & 0.0065 \\
\hline $18: 1_{n-9}$ & 0.0101 \\
\hline MUFA & 0.0059 \\
\hline MUFA/SFA & 0.0509 \\
\hline $18: 1_{n-9}$ et $n-7$ & 0.0104 \\
\hline cis $20: 5_{n-3}$ (EPA) & 0.0606 \\
\hline cis $22: 5 n-3$ (DPA) & 0.2651 \\
\hline cis $22: 6_{n-3}$ (DHA) & 0.1081 \\
\hline Total n-3 PUFA & 0.3299 \\
\hline Unsaturated/saturated fatty acid & 0.3179 \\
\hline $\mathrm{n}-6 / \mathrm{n}-3$ PUFA & 0.5089 \\
\hline$L A / A L A$ & 0.674 \\
\hline$A A / D H A$ & 0.3199 \\
\hline \multicolumn{2}{|l|}{ Fatty acids (lipidomics analysis) } \\
\hline 3-Hydroxyadipic acid & 0.3109 \\
\hline$N$-formylmaleamic acid & 0.3362 \\
\hline Dodecatetraenedioic acid & 0.1633 \\
\hline Linderic acid & 0.1977 \\
\hline alpha-hydroxy lauric acid & 0.0993 \\
\hline 3-oxo-4-pentenoic acid & 0.2546 \\
\hline Dehydrocholic acid & 0.3842 \\
\hline $7 R, 9,14 R$-trimethyl-2E,4E,8E,10E-hexadecatetraenoic acid & 0.3054 \\
\hline \multicolumn{2}{|l|}{ Ceramide } \\
\hline Cer(d18:1/24:0) & 0.2395 \\
\hline \multicolumn{2}{|l|}{ Sphingomyeline } \\
\hline SM (d18:0/12:0) & 0.0919 \\
\hline SM (d18:1/12:0) & 0.4359 \\
\hline SM (18:1/14:0) & 0.6205 \\
\hline SM (18:1/20:1) & 0.3694 \\
\hline SM (d18:1/20:2) & 0.2828 \\
\hline SM (d18:1/23:0) & 0.8853 \\
\hline $\mathrm{SM}(\mathrm{d} 18: 1 / 24: 0)$ & 0.1673 \\
\hline \multicolumn{2}{|l|}{ Glucosy/Galactosyl-Ceramide } \\
\hline GlucosylCeramide (d18:1/18:0) & 0.5277 \\
\hline \multicolumn{2}{|l|}{ Phosphatidylcholine } \\
\hline PC (18:0/18:1) & 0.0445 \\
\hline PC (20:0/20:2) & 0.3251 \\
\hline PC (16:1/18:2) & 0.7613 \\
\hline PC (18:1/18:1) & 0.6294 \\
\hline PC (18:0/18:2) & 0.8524 \\
\hline PC (16:0/20:3) & 0.3092 \\
\hline PC (18:0/20:3) & 0.4509 \\
\hline PC (20:1/20:4) & 0.8255 \\
\hline PC (20:3/22:6) & 0.2408 \\
\hline PC (16:0/22:6) & 0.6206 \\
\hline \multicolumn{2}{|l|}{ PC-plasmalogen } \\
\hline PC (P-18:0/18:0) & 0.6294 \\
\hline \multicolumn{2}{|l|}{ Phosphatidylethanolamine } \\
\hline PE (16:0/16:1) & 0.7887 \\
\hline PE (16:1/20:0) & 0.958 \\
\hline PE (16:0/20:2) & 0.3531 \\
\hline PE (18:0/20:4) & 0.4997 \\
\hline PE (22:0/20:3) & 0.9017 \\
\hline PE (18:2/18:2) & 0.8205 \\
\hline PE (20:0/18:1) & 0.4662 \\
\hline PE (20:4/20:0) & 0.7422 \\
\hline PE (20:3/22:6) & 0.0497 \\
\hline PE (18:0/20:3) & 0.1121 \\
\hline
\end{tabular}


Table 4. Cont.

\begin{tabular}{|c|c|}
\hline & $\begin{array}{l}\text { Infant' Weight Growth between Birth and } \\
\text { Discharge (SD) ( } p \text {-Value Corrected-MLR) }\end{array}$ \\
\hline \multicolumn{2}{|l|}{ PE-plasmalogen } \\
\hline PE (O-18:0/20:5) & 0.0331 \\
\hline \multicolumn{2}{|l|}{ Phosphatidylglycerol } \\
\hline PG (P-16:0/22:4) & 0.846 \\
\hline PG $(18: 2 / 20: 5)$ & 0.3118 \\
\hline PG (22:2/22:6) & 0.2912 \\
\hline \multicolumn{2}{|l|}{ Diacylglyceride } \\
\hline DG (20:3:/20:0) & 0.2475 \\
\hline \multicolumn{2}{|l|}{ Triglyceride } \\
\hline TG $(14: 0 / 16: 0 / 16: 0)$ & 0.1971 \\
\hline TG (14:0/14:1/19:1) & 0.5987 \\
\hline TG (16:0/16:1/16:1) & 0.9338 \\
\hline TG $(14: 0 / 16: 0 / 16: 0)$ & 0.7951 \\
\hline TG (16:0/17:1/18:1) & 0.0122 \\
\hline TG (16:1/16:1/18:2) & 0.6581 \\
\hline TG $(16: 0 / 16: 0 / 16: 1)$ & 0.9685 \\
\hline TG (16:1/18:4/18:4) & 0.0034 \\
\hline TG (18:2/18:2/20:0) & 0.8228 \\
\hline TG (18:0/18:1/18:1) & 0.066 \\
\hline TG (18:1/18:1/18:2) & 0.4819 \\
\hline TG (18:1/18:2/18:2) & 0.4212 \\
\hline TG $(16: 0 / 17: 1 / 20: 5)$ & 0.9923 \\
\hline TG $(18: 1 / 18: 2 / 20: 0)$ & 0.3693 \\
\hline TG $(18: 1 / 20: 2 / 20: 4)$ & 0.5425 \\
\hline \multicolumn{2}{|l|}{ Eicosanoïd } \\
\hline 10,11-dihydro-20-trihydroxy-leukotriene B4 & 0.909 \\
\hline Leukotriene B4 & 0.3869 \\
\hline 15S-HpEDE & 0.0042 \\
\hline 11-deoxy-16,16-dimethyl-PGE2 & 0.0017 \\
\hline 9-deoxy-9-methylene-16,16-dimethyl-PGE2 & 0.0075 \\
\hline PGF2alpha & 0.2057 \\
\hline 11-dehydro-2,3-dinor-TXB2 & 0.5135 \\
\hline \multicolumn{2}{|l|}{ Lyso PS/PG } \\
\hline LysoPS (22:0) & 0.0849 \\
\hline LysoPG (22:4) & 0.0741 \\
\hline LysoPA $(20: 0)$ & 0.9564 \\
\hline \multicolumn{2}{|l|}{ Cardiolipine } \\
\hline CL (18:1/18:1/20:4/18:0) & 0.3702 \\
\hline
\end{tabular}

Values of $p$-values were calculated using multiple linear regression analysis, by taking into account several confounding factors (infant's birth weight, mother's BMI, gestational age, complementary parenteral and enteral nutrition with the protein, lipid and energy intakes, duration of parenteral feeding and ventilation, and length of hospital stay). Statistical significance was set to a confidence level of $p<0.10$ ( $p$-values in bold font).

Among the 50 AoV-PLS/LDA- and/or FDR-selected biomarkers, nine lipid species appeared of paramount interest, due to their significant (10\%) MLR $p$-value for delta weight Z-score [two MCSAT, lauric (C12:0) and myristic (C14:0) acids; one MUFA, oleic (C18:1) acid; a medium-chain SM, SM (d18:0/12:0); a PE-plasmalogen containing stearic and EPA acid [PE (O-18:0/20:5)]; and two long-chain Lyso-PLs [LysoPS (22:0) and LysoPG (22:4)]; a PC-containing stearic and oleic acid, PC (18:0/18:1); a PE-containing DGLA and DHA, PE (20:3/22:6); DGLA-derived oxylipins [15S-HpEDE and two deoxy-dimethyl-PGE2]; and two TG-containing palmitoleic or oleic acid [TG (16:1/18:4/18:4), TG (16:0/17:1/18:1) and TG (18:0/18:1/18:1)]. The AUC of ROC curve of these nine lipid species ranged $0.6-0.7$, indicating a reasonably good performance of these selected biomarkers to predict preterm infant weight growth during their first four postnatal weeks (as illustrated in Figure 5). 

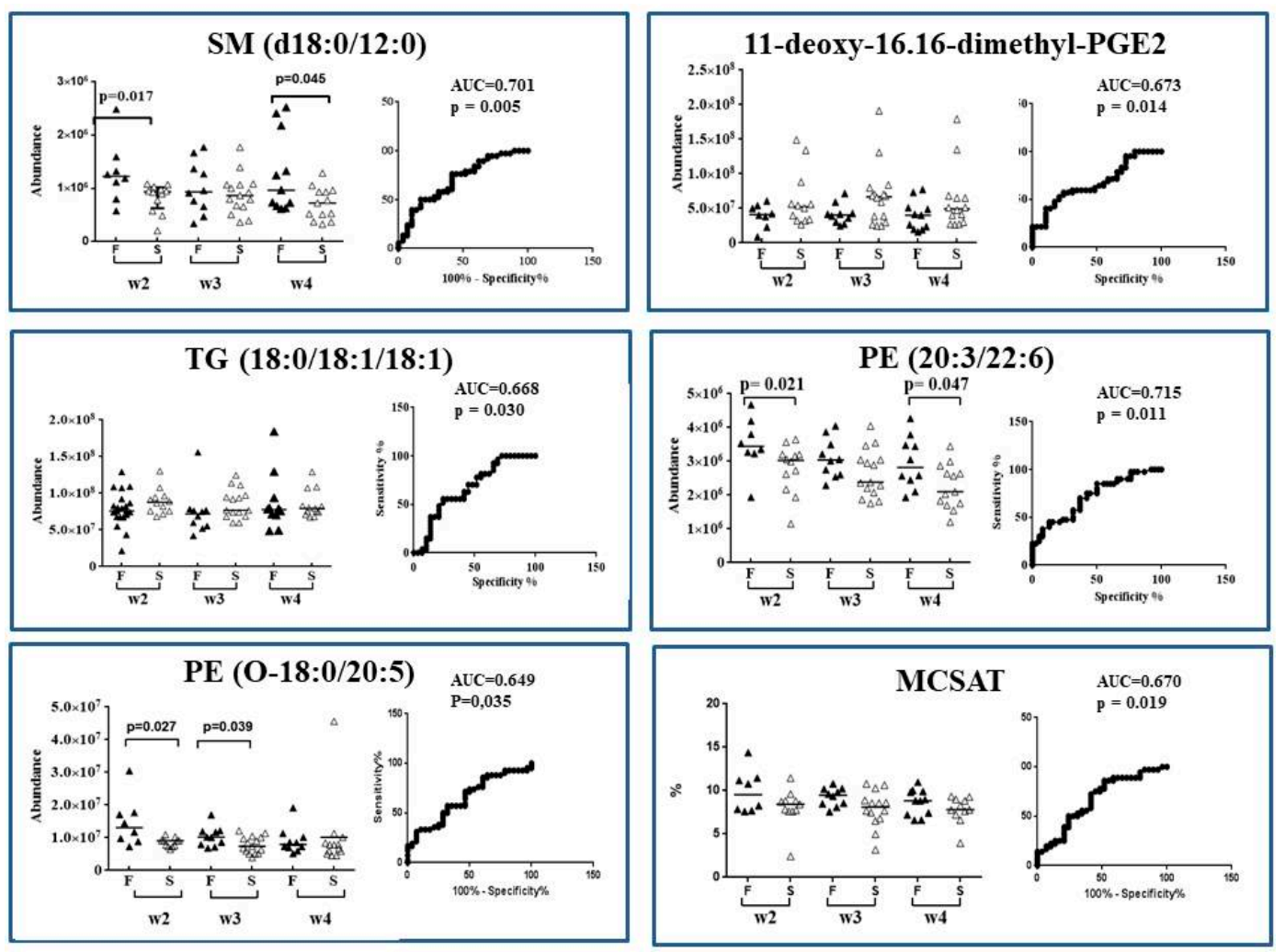

Figure 5. Scatter plot and ROC plot analysis using lipids biomarkers abundance (SM (d18:0/12:0), TG (18:0/18:1/18:1), PE (O-18:0/20:5), PE (20:3/22:6), MCSAT and one deoxy-dimethyl-PGE2) in breast milk provided to preterm infants who experienced "faster" (black triangle, F group) versus "slower" (white triangle, $\mathrm{S}$ group) growth during hospital stay. Scatter plot (median): from w2 to w4 of lactation period; ROC plot: over the entire W2-W4 lactation period. $\Delta$ Faster growth group (F); $\Delta$ slower growth group (S).

\section{Discussion}

To the best of our knowledge, the current pilot study is the first to demonstrate that clear-cut differences in breast milk lipidomic signature are associated with the early growth pattern of preterm infants receiving their own mother's breast milk as their sole source of enteral feeding for the first month of life. Our strategy was to compare two groups of preterm infants who presented opposite growth velocity during their hospital stay. Infants in our "faster" growth group (mean birth weight Z-score -1.59 SD) lost less than $0.67 \mathrm{SD}$ weight Z-scores between birth and discharge, indicating nearly optimal growth during their hospitalization. In contrast, infants in our "slower" growth group (mean birth weight $Z$-score $0.56 \mathrm{SD}$ ) lost more than $-1.10 \mathrm{SD}$ (range $-1.953 ;-1.230$ ) weight $Z$-scores between birth and discharge, indicating sub-optimal growth. These mean weight $Z$-score at discharge are nearly identical to the first and third tercile identified in a larger preterm cohort described earlier by our team [40]. A negative correlation between birth weight and early growth (between birth and hospital discharge) has long been known in cohorts of preterm infants [40,43]. We therefore introduced birth weight as one of the clinical parameters in the adjustment variables in Multiple Linear Regression (MLR) analysis. The latter model made it possible to check the reliability of potential biomarkers. In the following discussion, we focus on the biomarkers that remained significant after adjustment in MLR. 


\section{1. "Faster" Growth during Hospital Stay Is Associated with a Specific Maternal Milk Lipidomic Signature}

We are aware of the fact that breast milk lipidomic signatures require ad hoc methods to assess the relevance of putative lipid biomarkers of preterm infant growth. For this purpose, we combined different multivariate statistical supervised models (MG PLS-DA, AoV-PLS followed to LDA), with various validation procedures [63]. These models allowed us to retrieve a set of 162 annotated lipids that contributed to breast-milk lipidotypes' clustering associated to infants presenting "faster" or "slower" growth. The intermediate clustering of lipidotypes in AoV-PLS score plot for breast milk provided to the two sets of twins with discordant growth rates, suggests that postnatal growth rate is obviously multifactorial, and postnatal feeding is undoubtedly one of these factors. Stringency in our analysis was ensured by taking into account confounding clinical factors for the selection of biomarkers. Then, among the 50 FDR-selected lipids biomarkers, nine displayed good performance measures of infant's weight gain during hospital stay, computed through a ROC curve [64], and a significant corrected MLR $p$-value for weight delta Z-score. The performance of ROC curve remained unchanged when discarding the two sets of twins who had discordant growth trajectories. This result suggests the reliability of the selected lipid species in the prediction of postnatal infant growth. These lipids present in breast milk therefore could be considered as robust candidate biomarkers of infant growth during hospital stay, in addition to classical determinants of postnatal growth of preterm infants during hospitalization such as birth weight, gestational age, development of comorbidities and protein/energy ratio in nutrition support [40]. It should be noted that the volume of milk intake, known to have a strong impact on early growth, was introduced in the Multiple Linear Regression model through the estimation of the total caloric intake. In the following, we therefore address the relevance of such putative MLR-significant biomarkers for preterm infant growth.

\subsection{The Abundance of Mcsat in Breast Milk Is Associated with "Faster" Growth during Hospital Stay}

Milk provided to preterm infants with "faster" growth contained more total MCSAT than milk provided to infants with "slower" growth. MCSAT may be important for the normal maturation of the gastrointestinal tract [65] and its protection from infection [66,67]. Moreover, MCSAT, and particularly lauric and myristic acids, are extensively oxidized [68]. Such an extensive oxidization leads to produce a dose-dependent rise in plasma ketones [69]. Ketones are a major source of both energy and acetyl-CoA not only for the brain development [69] but also for overall body growth. Such role of MCSAT could explain the association of MCSAT-rich milk with "faster" growth in our cohort.

\subsection{Medium-Chain Sphingomyelins and Choline-Containing Phospholipids in Breast Milk Reliably Predict Early Growth in Preterm Infant}

Infants with a faster growth received breast milk with a higher content in a medium-chain sphingomyelin SM (d18:0/12:0) and long chain choline-containing PLs:PC (18:0/18:1) and PE (20:3/22:6). In adults, medium chain-ceramides were found to enhance insulin sensitivity and improve glucose homeostasis [70,71]. Such an impact has not yet been explored in infants. Phosphatidylcholine and sphingomyelin were reported to protect against gastrointestinal infection, during early childhood, and to play a key role in gut barrier function [67]. With regard with phospholipids containing PUFAs, they may act as antioxidants in gut mucosa [72]. Finally, the abundance of phosphatidylcholine and sphingomyelin in breast milk implies that human milk supplies large amounts of choline, which is essential for neurodevelopment [32].

\subsection{Enhanced Breast Milk Levels of DHA-, Dihomo- $\gamma$-Linolenic Acid-and Plasmalogen-Containing PE Are Associated with "Faster" Growth in Preterm Neonates}

Breast milk provided to preterm infants with "faster" growth contained more DGLA- and DHA-containing PE (PE (20:3/22:6)). Such finding is consistent with the beneficial effects of DGLA reported in the treatment of inflammatory disorders and in cholesterol homeostasis [73]. Interestingly, our lipidomics study confirms the presence of plasmalogens from the PE (Pls-PEs) family. This 
has been previously reported in human milk [74] with a potential impact on infant health [66]. With respect with our data, the plasmalogen PE (O-18:0/20:5) containing EPA, a precursor of DHA, presented a significant MLR $p$-value corrected for both weight gain and head circumference growth in preterm infants. In contrast, breast milk total EPA and DHA content did not predict head growth in our infants, even though higher levels of EPA and DHA were found in the "faster" growth group. Taken together, these findings suggest dietary DHA, provided as a phospholipid may be more efficient than DHA supplied as part of a triglyceride, for brain DHA accretion, as reported in piglets [75]. Human milk plasmalogens may be involved in infant brain development since brain Pls-PEs were recently shown to accumulate postnatally and to be enriched in long-chain PUFA, particularly DHA [76]. Brain plasmalogen content was reported to increase between the 32nd week of gestation and the 4th and 6th postnatal month [66]. Plasmalogens exert an antioxidant effect [66]. The lower erythrocyte levels of plasmalogens reported in neonates, compared to older children, could be detrimental in preterm infants who have decreased anti-oxidant defense [77,78]. However, the biological determinants of Pls-PE FAs and physiological relevance to the breastfed infant remain to be elucidated [76].

\subsection{Decreased Breast Milk Levels of Eicosanoids and Oleic Acid-Containing Triglycerides Are Associated with Early Weight Gain in Preterm Neonates}

Decreased levels in long-chain TG containing oleic (TG (18:0/18:1/18:1) and TG (16:0/17:1/18:1)) predicted infant growth. Dietary substitution of medium-chain for long-chain triglycerides was shown to affect energy balance, promoting weight reduction in obese, adult humans [68]. In preterm infants, the use of lipid emulsions containing 50\% medium-chain TG in parenteral nutrition was found to be associated with a lesser rate of protein accretion, compared to emulsions containing $100 \%$ long-chain TG [79]. Oleic acid may exert an anti-microbial activity and protect the digestive tract against infection [74]. However, it remains largely unexplored in infants [80]. Finally, among several eicosanoids that were less abundant in the breast milk provided to preterm infants' with "faster" growth, three dihomo- $\gamma$-linolenic acid (DGLA)-derived oxylipins (15S-HpEDE and two deoxy-dimethyl-PGE2) displayed predictive ability on infant growth during hospital stay. These oxylipins are signaling lipids very recently found in human milk $[73,81]$, and may play a role in preterm infant as pro- and/or anti-inflammatory mediators which could, in turn, exert key roles in maternal-infant biochemical imprinting [81]. Similarly, Lyso-phospholipids (LPLs) constitute another group of important lipid mediators with likely specific effects in infants that remained to be explored.

Taken in aggregate, the current findings suggest a striking inter-subject variation in the lipidome of breast milk among mothers who deliver preterm infants. Moreover, they suggest that such heterogeneity may impact early infant's growth.

Limitations of the study stem from the relatively small size of the sample, the exploratory character of the study, and slight differences in birth weight between the groups. It has long been known that infants born with a lower birthweight grow faster, and this was previously reported in the large LIFT cohort of 2277 preterm infants by our team [40] as well as in another cohort [43]. Matching groups for birth weight would, therefore, be nearly impossible. We therefore have to admit that we cannot determine whether the difference in lipid species observed between groups in the current study reflects: (a) the difference in birth weight; (b) in growth trajectory per se; or (c) a combination of both. Delineating the relative contribution of the latter two factors (birth weight and early growth trajectory) and validating the ability of putative lipid biomarkers to predict early growth rate would require larger cohort studies. Moreover, our finding in twins, who followed opposite trajectories during their hospital stay, illustrates the fact that breast milk lipid composition is only one among the many factors that determine early growth in preterm infants.

The main strength of the study lies in the rigorous and comprehensive approach used to discriminate breast milk lipidomic patterns between the infant groups that experienced "faster" growth 
versus "slower" growth in their first four postnatal weeks. Robust lipid biomarkers, i.e., medium-chain sphingomyelin [SM (d18:0/12:0)], phospholipid containing DGLA and DHA [PE (20:3/22:6)], DGLA-derived oxylipin, TG-containing oleic acid (TG (16:0/17:1/18:1) and TG (18:0/18:1/18:1)) and MCSAT, displayed a good ability to predict weight gain during hospital stay, likely through their role in energy homeostasis, or the defense against oxidative stress, gastrointestinal tract infection, or inflammation. In particular, we confirm the presence of some new bioactive lipids (oxylipin) recently evidenced in human milk with suggested biological relevance to preterm infant health [82]. Further research on milk bioactive-lipid components is warranted to improve our understanding of the biological role of breast milk fat and its impact on infant development and health. Such understanding could, in turn, open the way to the manipulation of maternal diet to produce desired changes in breast milk, and/or to the use of specific lipid supplements in the personalized nutritional care of preterm infants in the neonatal intensive care unit.

Supplementary Materials: The following are available online at http:/ /www.mdpi.com/2072-6643/10/2/164/s1,

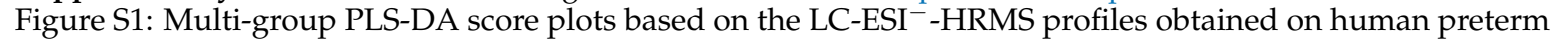
milk; Figure S2: AoV-PLS and LDA models, based on the LC-ESI--HRMS profiles of human preterm milk, on the factor weight $Z$-score (discharge-birth); Table S1: Concentration levels of total fatty acids expressed as \% of total identified FA, measured in human preterm milk at W2, W3, W4 of lactation and provided to newborns with "faster" or "slower" growth; Table S2: Abundance $\left(10^{6}\right)$ of annotated discriminant lipids measured in breast milk at week 2 (W2), W3, W4 of lactation provided to preterm infants with fast or slow growth.

Acknowledgments: This work was part of the LACTACOL project. The LACTACOL projet was funded by Région Pays-de-la-Loire (2011-2012) and by the "Fonds Européen de Développement Economique et Régional" (FEDER, Grant 38395, Project 6226, 2013-2015). We thank lactating mothers for having accepted donation of breast milk for the LACTACOL protocol, and Laure Simon, and Evelyne Gauvard for caring for mothers and their infants as well as guarantying the collection of maternal milk. We also thank the Biological Resource Centre for biobanking (CHU Nantes, Hôtel Dieu, Centre de Ressources Biologiques (CRB), Nantes, F-44093, France (BRIF: BB-0033-00040)) for storing human milk samples in the milk biobank (DC-2009-982).

Author Contributions: Marie-Cécile Alexandre-Gouabau, Jean-Christophe Rozé: had full access to all of the data in the study and took responsibility for the integrity of the data and the accuracy of the data analysis designed research; Clair-Yves Boquien, Jean-Christophe Rozé, Cécile Boscher, Dominique Darmaun, Arnaud Legrand: conceived the LACTACOL study and design; Cécile Boscher, Hélène Billard and Clair-Yves Boquien: managed the LACTACOL cohort; Marie-Cécile Alexandre-Gouabau: conceived and supervised the present lipidomics study conducted on a subset of infants of LACTACOL cohort; Thomas Moyon, Véronique Cariou, El Mostafa Qannari, Mohamed Soumah: conceived the appropriate statistical tools and/or performed the statistical analysis; Jean-Philippe Antignac, Agnès David-Sochard, Yann Guitton, Mikaël Croyal: conducted lipidomic analysis; Marie-Cécile Alexandre-Gouabau, Thomas Moyon, Véronique Cariou, Jean-Christophe Rozé and Dominique Darmaun: drafted the manuscript; Dominique Darmaun: critically revised the manuscript for important intellectual content; and all authors: acquired, analyzed, or interpreted the data, and read and approved the final manuscript.

Conflicts of Interest: No funder/sponsor had any role in the design and conduct of the study; collection, management, analysis, and interpretation of the data; the preparation, review, or approval of the manuscript; or the decision to submit the manuscript for publication.

\section{Abbreviations}

$\begin{array}{ll}\text { AA } & \text { arachidonic acid } \\ \text { ALNA } & \text { alpha-Linolenic acid } \\ \text { AoV-PLS } & \text { analysis of variance combined to partial least squares regression } \\ \text { AUC } & \text { area under the curve } \\ \text { CL } & \text { cardiolipine } \\ \text { DG } & \text { diacylglycerol } \\ \text { DGLA } & \text { dihomo-gamma-linolenic acid } \\ \text { DHA } & \text { docosahexanoic acid } \\ \text { GA } & \text { gestational age } \\ \text { GLNA } & \text { gamma-linolenic acid } \\ \text { EPA } & \text { eicosapentaenoic acid } \\ \text { ESI } & \text { electrospray ionization }\end{array}$




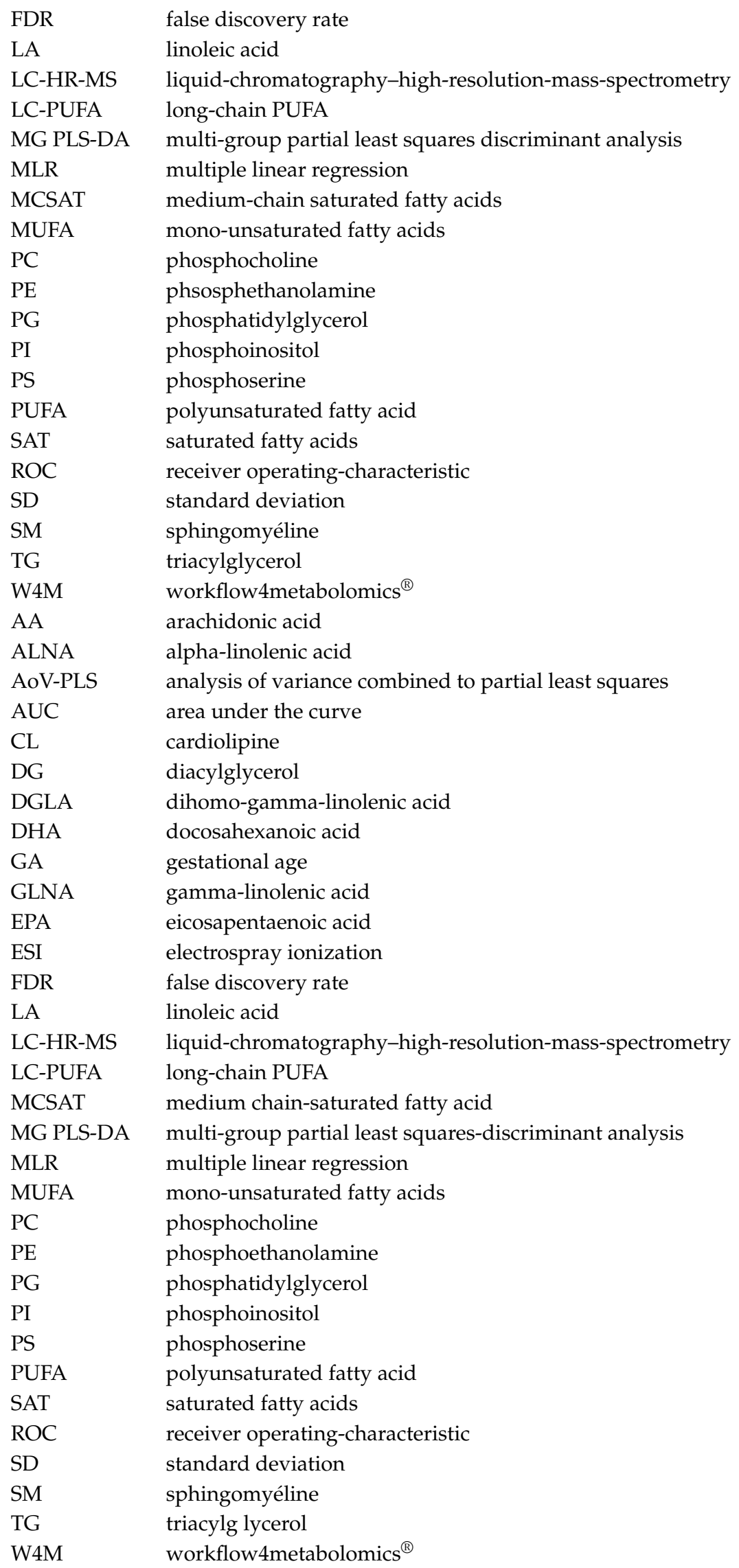




\section{References}

1. Victora, C.G.; Bahl, R.; Barros, A.J.; França, G.V.; Horton, S.; Krasevec, J.; Murch, S.; Sankar, M.J.; Walker, N.; Rollins, N.C.; et al. Breastfeeding in the 21st century: Epidemiology, mechanisms, and lifelong effect. Lancet 2016, 387, 475-490. [CrossRef]

2. World Health Organization; United Nations Children's Fund. Global Strategy for Infant and Young Child Feeding, 1st ed.; World Health Organization: Geneva, Switzerland, 2003; p. 30, ISBN 9241562218.

3. Schanler, R.J.; Hurst, N.M. The use of human milk and breastfeeding in premature infants. Clin. Perinatol. 1999, 26, 379-398. [CrossRef] [PubMed]

4. Callen, J.; Pinelli, J. A review of the literature examining the benefits and challenges, incidence and duration, and barriers to breastfeeding in preterm infants. Adv. Neonatal Care 2005, 5, 72-88. [CrossRef] [PubMed]

5. American Academy of Pediatrics. Section on Breastfeeding. Breastfeeding and the use of human milk. Pediatrics 2012, 129, e827-e841.

6. Arslanoglu, S.; Corpeleijn, W.; Moro, G.; Braegger, C.; Campoy, C.; Colomb, V.; Decsi, T.; Domellöf, M.; Fewtrell, M.; Hojsak, I.; et al. Donor human milk for preterm infants: Current evidence and research directions. J. Pediatr. Gastroenterol. Nutr. 2013, 57, 535-542. [CrossRef] [PubMed]

7. Corpeleijn, W.E.; de Waard, M.; Christmann, V.; van Goudoever, J.B.; Jansen-van der Weide, M.C.; Kooi, E.M.; Koper, J.F.; Kouwenhoven, S.M.P.; Hendrik, N.L.; Mank, E.; et al. Effect of donor milk on severe infections and mortality in very low-birth-weight infants: The early nutrition study randomized clinical trial. JAMA Pediatr. 2016, 170, 654-661. [CrossRef] [PubMed]

8. Kumar, R.K.; Singhal, A.; Vaidya, U.; Banerjee, S.; Anwar, F.; Rao, S. Optimizing nutrition in preterm low birth weight infants-Consensus summary. Front. Nutr. 2017, 4, 20. [CrossRef] [PubMed]

9. Johnson, T.J.; Patel, A.L.; Bigger, H.R.; Engstrom, J.L.; Meier, P.P. Economic benefits and costs of human milk feedings: A strategy to reduce the risk of prematurity-related morbidities in very-low-birth-weight infants. Adv. Nutr. Int. Rev. J. 2014, 5, 207-212. [CrossRef] [PubMed]

10. Quigley, M.; McGuire, W. Formula versus donor breast milk for feeding preterm or low birth weight infants. Cochrane Database Syst. Rev. 2014, CD002971. [CrossRef]

11. Meinzen-Derr, J.; Poindexter, B.; Wrage, L.; Morrow, A.L.; Stoll, B.; Donovan, E.F. Role of human milk in extremely low birth weight infants' risk of necrotizing enterocolitis or death. J. Perinatol. 2009, 29, 57-62. [CrossRef] [PubMed]

12. Rozé, J.C.; Ancel, P.Y.; Lepage, P.; Martin-Marchand, L.; Al Nabhani, Z.; Delannoy, J.; Picaud, J.C.; Lapillonne, A.; Aires, J.; Durox, M.; et al. Nutrition EPIPAGE 2 study group and the EPIFLORE Study Group. Nutritional strategies and gut microbiota composition as risk factors for necrotizing enterocolitis in very-preterm infants. Am. J. Clin. Nutr. 2017, 106, 821-830. [CrossRef] [PubMed]

13. Boyd, C.A.; Quigley, M.A.; Brocklehurst, P. Donor breast milk versus infant formula for preterm infants: Systematic review and meta-analysis. Arch. Dis. Child. Fetal Neonatal Ed. 2007, 92, F169-F175. [CrossRef] [PubMed]

14. Rozé, J.C.; Darmaun, D.; Boquien, C.Y.; Flamant, C.; Picaud, J.C.; Savagner, C.; Claris, O.; Lapillonne, A.; Mitanchez, D.; Branger, B. The apparent breastfeeding paradox in very preterm infants: Relationship between breastfeeding, early weight gain and neurodevelopment based on results from two cohorts, EPIPAGE and LIFT. BMJ Open 2012, 2, e000834. [CrossRef] [PubMed]

15. Singhal, A.; Cole, T.J.; Fewtrell, M.; Lucas, A. Breastmilk feeding and lipoprotein profile in adolescents born preterm: Follow-up of a prospective randomised study. Lancet 2004, 363, 1571-1578. [CrossRef]

16. Curtis, M.; Rigo, J. Extrauterine growth restriction in very-low-birthweight infants. Acta Paediatr. 2004, 93, 1563-1568. [CrossRef] [PubMed]

17. Ehrenkranz, R.A.; Dusick, A.M.; Vohr, B.R.; Wrigh, L.L.; Wrage, L.A.; Poole, W.K. Growth in the neonatal intensive care unit influences neurodevelopmental and growth outcomes of extremely low birth weight infants. Pediatrics 2006, 117, 1253-1261. [CrossRef] [PubMed]

18. Larroque, B.; Ancel, P.Y.; Marret, S.; Marchand, L.; André, M.; Arnaud, C.; Pierrat, V.; Rozé, J.C.; Messer, J.; Thiriez, G.; et al. Neurodevelopmental disabilities and special care of 5-year-old children born before 33 weeks of gestation (the EPIPAGE study): A longitudinal cohort study. Lancet 2008, 371, 813-820. [CrossRef] 
19. Agostoni, C.; Buonocore, G.; Carnielli, V.; De Curtis, M.; Darmaun, D.; Decsi, T.; Domellöf, M.; Embleton, N.D.; Fusch, C.; Genzel-Boroviczeny, O. Enteral nutrient supply for preterm infants: Commentary from the European Society of Paediatric Gastroenterology, Hepatology and Nutrition Committee on nutrition. J. Pediatr. Gastroenterol. Nutr. 2010, 50, 85-91. [CrossRef] [PubMed]

20. Henriksen, C.; Westerberg, A.C.; Rønnestad, A.; Nakstad, B.; Veierød, M.B.; Drevon, C.A.; Iversen, P.O. Growth and nutrient intake among very-low-birth-weight infants fed fortified human milk during hospitalisation. Br. J. Nutr. 2009, 102, 1179-1186. [CrossRef] [PubMed]

21. Saarela, T.; Kokkonen, J.; Koivisto, M. Macronutrient and energy contents of human milk fractions during the first six months of lactation. Acta Paediatr. 2005, 94, 1176-1181. [CrossRef] [PubMed]

22. Innis, S.M. Human milk: Maternal dietary lipids and infant development. Proc. Nutr. Soc. 2007, 66, 397-404. [CrossRef] [PubMed]

23. Dingess, K.A.; Valentine, C.J.; Ollberding, N.J.; Davidson, B.S.; Woo, J.G.; Summer, S.; Peng, Y.M.; Guerrero, M.L.; Ruiz-Palacios, G.M.; Ran-Ressler, R.R.; et al. Branched-chain fatty acid composition of human milk and the impact of maternal diet: The Global Exploration of Human Milk (GEHM) study. Am. J. Clin. Nutr. 2017, 105, 177-184. [CrossRef] [PubMed]

24. Mäkelä, J.; Linderborg, K.; Niinikoski, H.; Yang, B.; Lagström, H. Breast milk fatty acid composition differs between overweight and normal weight women: The STEPS Study. Eur. J. Nutr. 2013, 52, 727-735. [CrossRef] [PubMed]

25. Bachour, P.; Yafawi, R.; Jaber, F.; Choueiri, E.; Abdel-Razzak, Z. Effects of smoking, mother's age, body mass index, and parity number on lipid, protein, and secretory immunoglobulin A concentrations of human milk. Breastfeed. Med. 2012, 7, 179-188. [CrossRef] [PubMed]

26. Ilcol, Y.O.; Hizli, B. Active and total ghrelin concentrations increase in breast milk during lactation. Acta Paediatr. 2007, 96, 1632-1639. [CrossRef] [PubMed]

27. Lubetzky, R.; Littner, Y.; Mimouni, F.B.; Dollberg, S.; Mandel, D. Circadian variations in fat content of expressed breast milk from mothers of preterm infants. J. Am. Coll. Nutr. 2006, 25, 151-154. [CrossRef] [PubMed]

28. Giugliani, E.R.; Horta, B.L.; Loret de Mola, C.; Lisboa, B.O.; Victora, C.G. Effect of breastfeeding promotion interventions on child growth: A systematic review and meta-analysis. Acta Paediatr. 2015, 104, $20-29$. [CrossRef] [PubMed]

29. Gidrewicz, D.A.; Fenton, T.R. A systematic review and meta-analysis of the nutrient content of preterm and term breast milk. BMC Pediatr. 2014, 14, 216. [CrossRef] [PubMed]

30. Koletzko, B.; Agostoni, C.; Bergmann, R.; Ritzenthaler, K.; Shamir, R. Physiological aspects of human milk lipids and implications for infant feeding: A workshop report. Acta Paediatr. 2011, 100, 1405-1415. [CrossRef] [PubMed]

31. Gurnida, D.A.; Rowan, A.M.; Idjradinata, P.; Muchtadi, D.; Sekarwana, N. Association of complex lipids containing gangliosides with cognitive development of 6-month-old infants. Early Hum. Dev. 2012, 88, 595-601. [CrossRef] [PubMed]

32. Verardo, V.; Gomez-Caravaca, A.M.; Arraez-Roman, D.; Hettinga, K. Recent advances in phospholipids from colostrum, milk and dairy by-products. Int. J. Mol. Sci. 2017, 18, 173. [CrossRef] [PubMed]

33. Alexandre-Gouabau, M.C.; Courant, F.; Le Gall, G.; Moyon, T.; Darmaun, D.; Parnet, P.; Coupe, B.; Antignac, J.P. Offspring metabolomic response to maternal protein restriction in a rat model of Intrauterine Growth Restriction (IUGR). J. Proteome Res. 2011, 10, 3292-3302. [CrossRef] [PubMed]

34. Fanos, V.; Atzori, L.; Makarenko, K.; Melis, G.B.; Ferrazzi, E. Metabolomics application in maternal-fetal medicine. Biomed. Res. Int. 2013. [CrossRef] [PubMed]

35. German, J.B.; Dillard, C.J. Composition, structure and absorption of milk lipids: A source of energy, fat-soluble nutrients and bioactive molecules. Crit. Rev. Food Sci. Nutr. 2006, 46, 57-92. [CrossRef] [PubMed]

36. Marincola, F.C.; Noto, A.; Caboni, P.; Reali, A.; Barberini, L.; Lussu, M.; Murgia, F.; Santoru, M.L.; Atzori, L.; Fanos, V. A metabolomic study of preterm human and formula milk by high resolution NMR and GC/MS analysis: Preliminary results. J. Matern. Fetal Neonatal Med. 2012, 25, 62-67. [CrossRef] [PubMed]

37. Wu, J.; Domellöf, M.; Zivkovic, A.M.; Larsson, G.; Öhman, A.; Nording, M.L. NMR-based metabolite profiling of human milk: A pilot study of methods for investigating compositional changes during lactation. Biochem. Biophys. Res. Commun. 2016, 469, 626-632. [CrossRef] [PubMed] 
38. Andreas, N.J.; Hyde, M.J.; Gomez-Romero, M.; Lopez-Gonzalvez, M.A.; Villasenor, A.; Wijeyesekera, A.; Barbas, C.; Modi, N.; Holmes, E.; Garcia-Perez, I. Multiplatform characterization of dynamic changes in breast milk during lactation. Electrophoresis 2015, 36, 2269-2285. [CrossRef] [PubMed]

39. Ancel, P.Y.; Goffinet, F.; Kuhn, P.; Langer, B.; Matis, J.; Hernandorena, X.; Chabanier, P.; Joly-Pedespan, L.; Lecomte, B.; Vendittelli, F.; et al. Survival and morbidity of preterm children born at 22 through 34 weeks' gestation in France in 2011: Results of the EPIPAGE-2 cohort study. JAMA Pediatr. 2015, 169, 230-238. [CrossRef] [PubMed]

40. Simon, L.; Frondas-Chauty, A.; Senterre, T.; Flamant, C.; Darmaun, D.; Rozé, J.C. Determinants of body composition in preterm infants at the time of hospital discharge. Am. J. Clin. Nutr. 2014, 100, 98-104. [CrossRef] [PubMed]

41. Cole, T.J. The LMS method for constructing normalized growth standards. Eur. J. Clin. Nutr. 1990, 44, 45-60. [PubMed]

42. Olsen, I.E.; Groveman, S.A.; Lawson, M.L.; Clark, R.H.; Zemel, B.S. New intrauterine growth curves based on United States data. Pediatrics 2010, 125, e214-e224. [CrossRef] [PubMed]

43. Steward, D.K.; Pridham, K.F. Growth patterns of extremely low-birth-weight hospitalized preterm infants. J. Obstet. Gynecol. Neonatal Nurs. 2002, 31, 57-65. [CrossRef] [PubMed]

44. Billard, H.; Simon, L.; Desnots, E.; Sochard, A.; Boscher, C.; Riaublanc, A.; Alexandre-Gouabau, M.C.; Boquien, C.Y. Calibration adjustment of the mid-infrared analyzer for an accurate determination of the macronutrient composition of human milk. J. Hum. Lact. 2016, 32, NP19-NP27. [CrossRef] [PubMed]

45. Bligh, E.; Dyer, W.J. A rapid method of total lipid extraction and purification. Can. J. Biochem. Physiol. 1959, 37, 911-917. [CrossRef] [PubMed]

46. Martin Agnoux, A.; Antignac, J.P.; Desnots, E.; Ferchaud-Roucher, V.; Darmaun, D.; Parnet, P.; Alexandre-Gouabau, M.C. Perinatal protein restriction effect on milk free amino acids and fatty acids profile in lactating rats and its potential role on growth and metabolic status of the pups. J. Nutr. Biochem. 2015, 26, 784-795. [CrossRef] [PubMed]

47. Gallart-Ayala, H.; Courant, F.; Severe, S.; Antignac, J.P.; Morio, F.; Abadie, J.; Le Bizec, B. Versatile lipid profiling by liquid chromatography-high resolution mass spectrometry using all ion fragmentation and polarity switching. Preliminary application for serum samples phenotyping related to canine mammary cancer. Anal. Chim. Acta 2013, 796, 75-83. [CrossRef] [PubMed]

48. Kessner, D.; Chambers, M.; Burke, R.; Agus, D.; Mallick, P. ProteoWizard: Open source software for rapid proteomics tools development. Bioinformatics 2008, 24, 2534-2536. [CrossRef] [PubMed]

49. Giacomoni, F.; Le Corguillé, G.; Monsoor, M.; Landi, M.; Pericard, P.; Pétéra, M.; Duperier, C.; Tremblay-Franco, M.; Martin, J.F.; Jacob, D.; et al. Workflow4Metabolomics: A collaborative research infrastructure for computational metabolomics. Bioinformatics 2015, 31, 1493-1495. [CrossRef] [PubMed]

50. Smith, C.A.; Want, E.J.; O'Maille, G.; Abagyan, R.; Siuzdak, G. XCMS: Processing mass spectrometry data for metabolite profiling using nonlinear peak alignment, matching, and identification. Anal. Chem. 2006, 78, 779-787. [CrossRef] [PubMed]

51. Kuhl, C.; Tautenhahn, R.; Bottcher, C.; Larson, T.R.; Neumann, S. CAMERA: An integrated strategy for compound spectra extraction and annotation of liquid chromatography/mass spectrometry data sets. Anal. Chem. 2011, 84, 283-289. [CrossRef] [PubMed]

52. Van Der Kloet, F.M.; Bobeldijk, I.; Verheij, E.R.; Jellema, R.H. Analytical error reduction using single point calibration for accurate and precise metabolomic phenotyping. J. Proteome Res. 2009, 8, 5132-5141. [CrossRef] [PubMed]

53. Dunn, W.B.; Broadhurst, D.; Begley, P.; Zelena, E.; Francis-McIntyre, S.; Anderson, N.; Brown, M.; Knowles, J.D.; Halsall, A.; Haselden, J.N. Procedures for large-scale metabolic profiling of serum and plasma using gas chromatography and liquid chromatography coupled to mass spectrometry. Nat. Protoc. 2011, 6, 1060-1083. [CrossRef] [PubMed]

54. Ferchaud-Roucher, V.; Croyal, M.; Krempf, M.; Ouguerram, K. Plasma lipidome characterization using UHPLC-HRMS and ion mobility of hypertriglyceridemic patients on nicotinic acid. Atherosclerosis 2015, 241, e123-e124. [CrossRef]

55. Van den Berg, R.A.; Hoefsloot, H.C.; Westerhuis, J.A.; Smilde, A.K.; van der Werf, M.J. Centering, scaling, and transformations: Improving the biological information content of metabolomics data. BMC Genom. 2006, 7, 142. [CrossRef] [PubMed] 
56. Eslami, A.; Qannari, E.M.; Kohler, A.; Bougeard, S. Multi-Group PLS Regression: Application to epidemiology. In New Perspectives in Partial Least Squares and Related Methods; Springer: New York, NY, USA, 2013; pp. 243-255. [CrossRef]

57. Eslami, A.; El Mostafa Qannari, S.B.; Sanchez, G.; Bougeard, S.; Eslami, M.A. Package ‘multigroup'. CRAN, Comprehensive R Archive Network for the R Programming Language. Available online: https:/ / cran.rproject.org / package=multigroup (accessed on 12 April 2017).

58. Harrington, P.D.B.; Vieira, N.E.; Espinoza, J.; Nien, J.K.; Romero, R.; Yergey, A.L. Analysis of varianceprincipal component analysis: A soft tool for proteomic discovery. Anal. Chim. Acta 2005, 544, 118-127. [CrossRef]

59. Smilde, A.K.; Jansen, J.J.; Hoefsloot, H.C.; Lamers, R.J.A.; Van Der Greef, J.; Timmerman, M.E. ANOVAsimultaneous component analysis (ASCA): A new tool for analyzing designed metabolomics data. Bioinformatics 2005, 21, 3043-3048. [CrossRef] [PubMed]

60. El Ghaziri, A.; Qannari, E.M.; Moyon, T.; Alexandre-Gouabau, M.C. AoV-PLS: A new method for the analysis of multivariate data depending on several factors. Electron. J. App. Stat. Anal. 2015, 8, 214-235. [CrossRef]

61. Tenenhaus, M. La Régression P, Pratique. Te; Editions Technip: Paris, France, 1998; ISBN 2-7108-0735-1.

62. Sanchez, G. DiscriMiner: Tools of the Trade for Discriminant Analysis. 2012. Available online: http:/ /CRAN. R-project.org / package=DiscriMiner (accessed on 1 December 2013).

63. Westerhuis, J.A.; Hoefsloot, H.C.; Smit, S.; Vis, D.J.; Smilde, A.K.; van Velzen, E.J.; van Duijnhoven, J.P.M.; van Dorsten, F.A. Assessment of PLSDA cross validation. Metabolomics 2008, 4, 81-89. [CrossRef]

64. Xia, J.; Sinelnikov, I.V.; Han, B.; Wishart, D.S. MetaboAnalyst 3.0-Making metabolomics more meaningful. Nucleic Acids Res. 2015, 43, W251-W257. [CrossRef] [PubMed]

65. Andreas, N.J.; Kampmann, B.; Le-Doare, K.M. Human breast milk: A review on its composition and bioactivity. Early Hum. Dev. 2015, 91, 629-635. [CrossRef] [PubMed]

66. Garcia, C.; Lutz, N.W.; Confort-Gouny, S.; Cozzone, P.; Armand, M.; Bernard, M. Phospholipid fingerprints of milk from different mammalians determined by 31 P NMR: Towards specific interest in human health. Food Chem. 2012, 135, 1777-1783. [CrossRef] [PubMed]

67. Contarini, G.; Povolo, M. Phospholipids in milk fat: Composition, biological and technological significance, and analytical strategies. Int. J. Mol. Sci. 2013, 14, 2808-2831. [CrossRef] [PubMed]

68. Mills, S.; Ross, R.P.; Hill, C.; Fitzgerald, G.F.; Stanton, C. Milk intelligence: Mining milk for bioactive substances associated with human health. Int. Dairy J. 2011, 21, 377-401. [CrossRef]

69. Innis, S.M. Impact of maternal diet on human milk composition and neurological development of infants. Am. J. Clin. Nutr. 2014, 99, 734S-741S. [CrossRef] [PubMed]

70. Taltavull, N.; Ras, R.; Mariné, S.; Romeu, M.; Giralt, M.; Méndez, L.; Medina, I.; Ramos-Romero, S.; Torres, J.L.; Nogués, M.R. Protective effects of fish oil on pre-diabetes: A lipidomic analysis of liver ceramides in rats. Food Funct. 2016, 7, 3981-3988. [CrossRef] [PubMed]

71. Montgomery, M.K.; Brown, S.H.; Lim, X.Y.; Fiveash, C.E.; Osborne, B.; Bentley, N.L.; Braude, J.P.; Mitchell, T.W.; Coster, A.C.F.; Don, A.S.; et al. Regulation of glucose homeostasis and insulin action by ceramide acyl-chain length: A beneficial role for very long-chain sphingolipid species. Biochim. Biophys. Acta Mol. Cell. Biol. Lipids 2016, 1861, 1828-1839. [CrossRef] [PubMed]

72. Grażyna, C.; Hanna, C.; Adam, A.; Magdalena, B.M. Natural antioxidants in milk and dairy products. Int. J. Dairy Technol. 2017, 70, 165-178. [CrossRef]

73. Wu, J.; Gouveia-Figueira, S.; Domellöf, M.; Zivkovic, A.M.; Nording, M.L. Oxylipins, endocannabinoids, and related compounds in human milk: Levels and effects of storage conditions. Prostaglandins Lipid Mediat. 2016, 122, 28-36. [CrossRef] [PubMed]

74. Garcia, C.; Duan, R.D.; Brévaut-Malaty, V.; Gire, C.; Millet, V.; Simeoni, U.; Bernard, M.; Armand, M. Bioactive compounds in human milk and intestinal health and maturity in preterm newborn: An overview. Cell. Mol. Biol. 2013, 59, 108-131. [CrossRef] [PubMed]

75. Liu, L.; Bartke, N.; van Daele, H.; Lawrence, P.; Qin, X.; Park, H.G.; Brenna, J.T. Higher efficacy of dietary DHA provided as a phospholipid than as a triglyceride for brain DHA accretion in neonatal piglets. J. Lipid Res. 2014, 55, 531-539. [CrossRef] [PubMed]

76. Moukarzel, S.; Dyer, R.A.; Keller, B.O.; Elango, R.; Innis, S.M. Human milk plasmalogens are highly enriched in long-chain PUFAs. J. Nutr. 2016, 146, 2412-2417. [CrossRef] [PubMed] 
77. Alexandre-Gouabau, M.C.; Courant, F.; Moyon, T.; Küster, A.; Le Gall, G.; Tea, I.; Antignac, J.P.; Darmaun, D. Maternal and cord blood LC-HRMS metabolomics reveal alterations in energy and polyamine metabolism, and oxidative stress in very-low birth weight infants. J. Proteome Res. 2013, 12, 2764-2778. [CrossRef] [PubMed]

78. Küster, A.; Tea, I.; Ferchaud-Roucher, V.; Le Borgne, S.; Plouzennec, C.; Winer, N.; Rozé, J.C.; Robins, R.J.; Darmaun, D. Cord blood glutathione depletion in preterm infants: Correlation with maternal cysteine depletion. PLoS ONE 2011, 6, e27626. [CrossRef] [PubMed]

79. Liet, J.M.; Piloquet, H.; Marchini, J.S.; Maugère, P.; Bobin, C.; Rozé, J.C.; Darmaun, D. Leucine metabolism in preterm infants receiving parenteral nutrition with medium-chain compared with long-chain triacylglycerol emulsions. Am. J. Clin. Nutr. 1999, 69, 539-543. [PubMed]

80. Delplanque, B.; Gibson, R.; Koletzko, B.; Lapillonne, A.; Strandvik, B. Lipid quality in infant nutrition: Current knowledge and future opportunities. J. Pediatr. Gastroenterol. Nutr. 2015, 61, 8-17. [CrossRef] [PubMed]

81. Arnardottir, H.; Orr, S.K.; Dalli, J.; Serhan, C.N. Human milk proresolving mediators stimulate resolution of acute inflammation. Mucosal Immunol. 2016, 9, 757-766. [CrossRef] [PubMed]

82. Robinson, D.T.; Palac, H.L.; Baillif, V.; van Goethem, E.; Dubourdeau, M.; van Horn, L.; Martin, C.R. Long chain fatty acids and related pro-inflammatory, specialized pro-resolving lipid mediators and their intermediates in preterm human milk during the first month of lactation. Prostaglandins Leuk. Essent. Fat. Acids 2017, 121, 1-6. [CrossRef] [PubMed]

(C) 2018 by the authors. Licensee MDPI, Basel, Switzerland. This article is an open access article distributed under the terms and conditions of the Creative Commons Attribution (CC BY) license (http://creativecommons.org/licenses/by/4.0/). 